\title{
Analysis of variable chlorophyll fluorescence in microphytobenthos assemblages: implications of the use of depth-integrated measurements
}

\author{
João Serôdio* \\ Departamento de Biologia, Universidade de Aveiro, Campus de Santiago, 3810-193 Aveiro, Portugal
}

\begin{abstract}
Measurements of in vivo chlorophyll a fluorescence made non-invasively on microphytobenthos samples represent the depth integration of the fluorescence emitted at different depths within the sediment. The effects of depth integration on fluorescence parameters and implications for the calculation and interpretation of indices used in quenching analysis were studied using a simulation model based on fluorescence light curves ( $F_{\mathrm{s}}$ and $F_{\mathrm{m}}{ }^{\prime}$ vs $E$ curves), light attenuation coefficients, and microalgal biomass profiles. Results indicate that the use of depth-integrated fluorescence measurements leads to a significant light-dependent overestimation of the physiological value of the effective Photosystem II (PSII) quantum yield and of the relative electron transport rate, which may exceed $40 \%$ at saturating light levels. As a result, light curves derived from depth-integrated measurements appear to saturate at higher irradiances, or to be less photoinhibited when compared to the physiological response of the microalgae. Furthermore, they can vary due to changes in the vertical distribution of microalgal biomass not reflecting alterations in microalgal physiology. The results obtained from the numerical simulations were confirmed experimentally, and variations in fluorescence emission attributable to depth integration were also found in fluorescence light curves from the literature. A set of recursive equations was derived to allow the estimation of the physiological light response through the deconvolution of light curves computed from depth-integrated fluorescence measurements made on undisturbed samples.
\end{abstract}

KEY WORDS: Microphytobenthos - Chlorophyll fluorescence $\cdot$ Light curves · Depth integration · Light attenuation $\cdot$ Migratory rhythms $\cdot$ Sediment

\section{INTRODUCTION}

Chlorophyll a fluorescence quenching analysis is a powerful tool for assessing the physiological status of photosynthetic organisms. After its introduction for the study of phytoplankton ('pump-and-probe' technique; Mauzerall 1972, Falkowski et al. 1986) and of terrestrial plants (pulse amplitude modulation or 'PAM' technique; Schreiber et al. 1986), fluorescence quenching analysis has been applied to virtually all types of photosynthetic organisms or communities, including lichens (Jensen \& Feige 1991), macroalgae (Henley et al. 1991), corals (Warner et al. 1996), periphyton (Ivorra et al. 2000), ice microalgae (Kühl et al. 2001) and microbial mats (Schreiber et al. 2002). In particular, PAM fluorometry has become widely used for the study of intertidal sediment-inhabiting microalgal communities, or microphytobenthos (Serôdio 2003 and references therein). It provides information on the 2 main processes that affect the short-term variability in the photophysiological response of undisturbed assemblages: (1) changes in productive biomass associated with migratory rhythms, through the measurement of biomass-dependent parameters (Serôdio et al. 1997), and (2) changes in photosynthetic efficiency, through the determination of the ratio $\Delta F / F_{\mathrm{m}}{ }^{\prime}$ (see Table $1_{\text {; }}$ Genty et al. 1989, Kromkamp et al. 1998). Furthermore, this technique presents considerable operational advantages, the most important of which is the rapid and non-intrusive nature of the measurements, which is crucial for coping with the high temporal and spatial (vertical) variability that affects these communities and 
for avoiding disturbances in the microgradients in the photic zone of the sediment.

PAM fluorometry is based on the exposure of photosynthetic cells to 3 different types of light: (1) measuring or excitation light which induces the fluorescence emission detected by the fluorometer; (2) actinic light (ambient light or light provided by the fluorometer), under which the $F_{\mathrm{S}}$ level is recorded; (3) saturating light pulses, used to induce the $F_{\mathrm{m}}{ }^{\prime}$ or $F_{\mathrm{m}}$ levels. Both $F_{\mathrm{s}}$ and $F_{\mathrm{m}}{ }^{\prime}$ vary with actinic irradiance $E$, reflecting the gradual closure of Photosystem II (PSII) reaction centers and the build-up of non-photochemical dissipation of absorbed light energy, which are dependent on the physiological status of the microalgae and on the particular experimental conditions applied (growth conditions, light adaptation status, duration of light exposure, etc). For

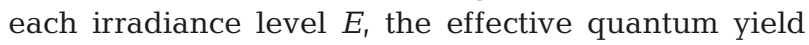
of charge separation at PSII can be calculated from $F_{\mathrm{s}}$ and $F_{\mathrm{m}}{ }^{\prime}$ by the ratio (Genty et al. 1989):

$$
\Delta F / F_{\mathrm{m}}{ }^{\prime}(E)=\frac{F_{\mathrm{m}}{ }^{\prime}(E)-F_{\mathrm{s}}(E)}{F_{\mathrm{m}}{ }^{\prime}(E)}
$$

where $\Delta F$ is the variable fluorescence. In the particular case of $E=0$, the fluorescence emitted from a darkadapted sample drops to the dark- or minimum-level fluorescence, $F_{0}$, and the saturating light pulses induce the maximum fluorescence level, $F_{\mathrm{m}}$.
An implicit fundamental assumption of the measurement of $\Delta F / F_{\mathrm{m}}$ ' is that all cells contributing to the measured fluorescence signal are (1) equally exposed to the measured level of actinic light, (2) exposed to light pulses which are effectively saturating and (3) equally exposed to measuring light and emitting equally detectable fluorescence. These assumptions are verified in dilute microalgal suspensions, where attenuation of all light types is negligible: all cells are equally exposed to actinic and saturating light, and all contribute equally to detected fluorescence. In this case, the obtained value of $\Delta F / F_{\mathrm{m}}$ ' represents the (similar) photophysiological response of all cells in the sample.

However, light conditions within microphytobenthos assemblages are very different. Sediments are optically dense, so that all types of light involved in the fluorescence measurement are subject to very strong attenuation, suffering complete extinction within the photosynthetically viable community. Therefore, the values of $F_{\mathrm{s}}$ and $F_{\mathrm{m}}{ }^{\prime}$ measured noninvasively at the surface of the sediment represent the integration of the $F_{\mathrm{s}}$ and $F_{\mathrm{m}}{ }^{\prime}$ levels emitted at different depths. Due to the vertical attenuation of downwelling measuring, actinic, and saturating light, and of upwelling fluorescence, the fluorescence levels measured at the surface include the contributions of emissions at different depths, which are exposed to irradiance levels different (lower) from those measured at the surface. Conse-

Table 1. Notation

\begin{tabular}{|c|c|}
\hline$a_{\text {meas }}, a_{\text {meas,chl }}$ & Absorption coefficient and chlorophyll-specific absorption coefficient of measuring light $\left(\mathrm{m}^{-1}, \mathrm{~m}^{2} \mathrm{mg}^{-1} \mathrm{chl} a\right)$ \\
\hline$\alpha, \beta$ & Initial slope and photoinhibition parameter of the ETR vs $E$ curve $\left[(\mu \mathrm{mol} \text { quanta })^{-1} \mathrm{~m}^{2} \mathrm{~s}\right]$ \\
\hline chl & Chlorophyll a concentration (mg chl $a \mathrm{~m}^{-3}$ ) \\
\hline$d$ & Subscript denoting a depth-integrated parameter \\
\hline$\Delta F / F_{\mathrm{m}}{ }^{\prime}$ & Effective quantum yield of PSII (dimensionless) \\
\hline$E_{1} E_{\text {meas }}$ & Spectrally averaged irradiance of PAR (400 to $700 \mathrm{~nm}$ ) and of measuring light ( $\mu \mathrm{mol}$ quanta $\mathrm{m}^{-2} \mathrm{~s}^{-1}$ ) \\
\hline$E_{\mathrm{k}}$ & Light-saturation parameter of the ETR vs $E$ curve ( $\mu$ mol quanta $\mathrm{m}^{-2} \mathrm{~s}^{-1}$ ) \\
\hline ETR & Relative electron transport rate (dimensionless) \\
\hline$E T R_{\mathrm{m}}$ & Maximum relative electron transport rate (dimensionless) \\
\hline$F_{\mathrm{s}}, F_{\mathrm{m}}{ }^{\prime}, \Delta F$ & $\begin{array}{l}\text { Steady-state, maximum and variable fluorescence }\left(=F_{\mathrm{m}}{ }^{\prime}-F_{\mathrm{s}}\right) \text { emitted by a light-adapted sample } \\
\text { (fluorescence units) }\end{array}$ \\
\hline$F_{\mathrm{s}}(E, z), F_{\mathrm{m}}{ }^{\prime}(E, z)$ & $F_{\mathrm{s}}, F_{\mathrm{m}}{ }^{\prime}$ emitted at depth $z$ under surface irradiance $E$ (fluorescence units $\mathrm{mm}^{-1}$ ) \\
\hline$F_{0}, F_{\mathrm{m}}$ & Minimum and maximum fluorescence emitted by a dark-adapted sample (fluorescence units) \\
\hline$\hat{F}_{\mathrm{s} \prime} \hat{F}_{\mathrm{m}}^{\prime}$ & $\begin{array}{l}\text { Estimates of } F_{\mathrm{s}} \text { and } F_{\mathrm{m}} \text { ' obtained by deconvolution of light curves based on depth-integrated parameters } \\
\text { (fluorescence units) }\end{array}$ \\
\hline$\phi F$ & Quantum yield of fluorescence [quanta emitted (quanta absorbed) ${ }^{-1}$ ] \\
\hline$G$ & $\begin{array}{l}\text { Conversion factor between detected fluorescent irradiance and fluorometer output } \\
\left.\text { [fluorescence units (quanta emitted } \mathrm{m}^{-2} \mathrm{~s}^{-1}\right)^{-1} \text { ] }\end{array}$ \\
\hline$k_{\mathrm{P}}, k_{\text {meas }}, k_{\mathrm{F}}$ & Diffuse attenuation coefficients of $E$, measuring light, and emitted fluorescence $\left(\mathrm{mm}^{-1}\right)$ \\
\hline$q_{\mathrm{P}}, q_{\mathrm{N}}$ & Photochemical and non-photochemical quenching \\
\hline$q_{\mathrm{E}}, q_{\mathrm{I}}, q_{\mathrm{T}}$ & Components of non-photochemical quenching \\
\hline$z_{1} z_{\mathrm{F}}$ & Depth and maximum depth where emitted fluorescence is detected at the surface (mm) \\
\hline
\end{tabular}


quently, the quantum yield calculated from depthintegrated measurements, $\Delta F / F_{\mathrm{m}}{ }^{\prime}{ }^{\mathrm{d}}$, may differ from the intrinsic value of $\Delta F / F_{\mathrm{m}}$ ' determined by the physiological status of the microalgae. While providing valuable information on the photophysiological characteristics of the community as a whole, $\Delta F / F_{\mathrm{m}}{ }^{\prime} \mathrm{d}$ may vary with factors not related to microalgal physiology, like the optical characteristics of the sediment or the vertical distribution of the microalgal biomass. A discrepancy between the values of $\Delta F / F_{\mathrm{m}}{ }^{\prime}$ of individual cells and of whole assemblages was measured by Oxborough et al. (2000), but its magnitude was not quantified and the implications regarding the applicability of the technique were not further investigated. Although on different spatial (vertical) scales, similar processes affect the interpretation of depth-integrated, solar-stimulated fluorescence emitted by marine phytoplankton; these processes have been studied in the context of oceanographic remote sensing (Neville \& Gower 1977, Gower \& Borstad 1990).

This study addresses the quantitative analysis of the effects associated with the use of depth-integrated fluorescence measurements on the determination of the effective PSII quantum yield in intact microphytobenthos samples. The inequality between $\Delta F / F_{\mathrm{m}}{ }^{\prime} \mathrm{d}$ and $\Delta F / F_{\mathrm{m}}{ }^{\prime}$ vs $E$ curves was first demonstrated theoretically, identifying light attenuation and vertical distribution of microalgal biomass and physiological characteristics within the photic zone of the sediment as the main factors determining its magnitude. The biases introduced by the use of depth-integrated measurements were quantified by calculating $\Delta F / F_{\mathrm{m} \text {,d }}{ }^{\prime}$ vs $E$ curves from $F_{\mathrm{s}}$ and $F_{\mathrm{m}}{ }^{\prime}$ vs $E$ curves, light attenuation coefficients and biomass profiles representing the widest documented variability under natural conditions. The predicted discrepancy between $\Delta F / F_{\mathrm{m}}{ }^{\prime}$ d and $\Delta F / F_{\mathrm{m}}$ ' vs $E$ curves was confirmed experimentally and by comparing published data measured on undisturbed and on resuspended microphytobenthos samples. A set of recursive equations is proposed to deconvolute $\Delta F / F_{\mathrm{m}, \mathrm{d}}{ }^{\prime}$ vs $E$ curves in order to estimate physiological $\Delta F / F_{\mathrm{m}}$ ' vs $E$ curves. Although the experimental data analysed in this study were obtained through PAM fluorometry, the theoretical considerations and the main conclusions are also applicable to other fluorometric techniques measuring variable fluorescence, such as Fast Repetition Rate Fluorometry (Gorbunov et al. 2001, Kromkamp \& Forster 2003).

\section{MATERIALS AND METHODS}

Theoretical inequality between $\Delta F / F_{\mathrm{m}}{ }^{\prime}$ and $\Delta F / F_{\mathrm{m}}{ }^{\prime} \mathrm{d}$. The fluorescence emission at each depth $z$ under surface actinic irradiance $E$ can be expressed as:

$$
F(E, z)=E_{\text {meas }}(z) a_{\text {meas }}(z) \phi F(E(z)) G
$$

with $E_{\text {meas }}(z)=E_{\text {meas }} \mathrm{e}^{-k_{\text {meas }} z}$ and $E(z)=E \mathrm{e}^{-k_{\mathrm{p}} z}$, and where $E_{\text {meas }}$ is the measuring irradiance at the surface, $a_{\text {meas }}$ is the absorption coefficient for measuring irradiance (that may be expressed as the product of chlorophyll-specific absorption coefficient, $a_{\text {meas,chl, }}$ and of chlorophyll a concentration, chl), $\phi F$ is the quantum yield of fluorescence, $k_{\text {meas }}$ and $k_{\mathrm{P}}$ are the diffuse attenuation coefficients for downwelling measuring and actinic irradiance (ambient photosynthetically active radiation, PAR, or white light provided by the fluorometer), and $G$ is a conversion factor between emitted fluorescent quanta and measurable arbitrary (instrument dependent) fluorescence units. In the case of the fluorometer used in this study (see below), both measuring and actinic light are provided by the same light source and therefore a single attenuation coefficient ( $\left.k_{\text {meas }}\right)$ needs to be considered. $\phi F$ varies with changes in environmental conditions and with the physiological status of the cells, determining the shape of the $F_{\mathrm{s}}$ and $F_{\mathrm{m}}{ }^{\prime}$ vs $E$ light curves and the values of the parameters $F_{0}$ and $F_{\mathrm{m}}$.

The fluorescence signal measured at the surface of undisturbed microphytobenthos samples represents the integration over depth of the fluorescence emitted at each depth $z$ (the rationale for $F_{\mathrm{m},{ }^{\prime} \mathrm{d}}$ is similar and omitted here for simplicity):

$$
F_{\mathrm{s}, \mathrm{d}}(E)=\int_{0}^{z_{\mathrm{F}}} F_{\mathrm{s}}(E, z) \mathrm{e}^{-k_{\mathrm{F}} z} \mathrm{~d} z
$$

(Fig. 1) where $z_{\mathrm{F}}$ is the maximum depth at which emitted fluorescence is detected at the surface, and $k_{\mathrm{F}}$ is the diffuse attenuation coefficient for upwelling fluorescence (integrated over the range of detectable wavelengths) (Serôdio et al. 2001). The effective quantum yield is calculated from depth-integrated fluorescence emissions $F_{\mathrm{s}, \mathrm{d}}$ and $F_{\mathrm{m}}{ }^{\prime} \mathrm{d}$, measured separately and non-invasively near the sample surface:

$$
\Delta F / F_{\mathrm{m}, \mathrm{d}}^{\prime}(E)=\frac{F_{\mathrm{m}, \mathrm{d}}{ }^{\prime}(E)-F_{\mathrm{s}, \mathrm{d}}(E)}{F_{\mathrm{m}, \mathrm{d}}{ }^{\prime}(E)}
$$

Because $\phi F$ varies with $E$ differently for $F_{\mathrm{s}}$ and for $F_{\mathrm{m}}{ }^{\prime}$ (different $F_{\mathrm{s}}$ and $F_{\mathrm{m}}{ }^{\prime}$ vs $E$ curves), and because depthintegrated measurements result from the integration over the light gradient between the surface and $z_{\mathrm{F}}$, the relationship between physiological and depth-integrated values will be different for $F_{\mathrm{s}}$ and for $F_{\mathrm{m}}$ '. As a consequence, the ratio of depth-integrated values given by Eq. (4) differs from $\Delta F / F_{\mathrm{m}}^{\prime}(E)$, predicting a discrepancy between the values computed from depthintegrated measurements and the true physiological, depth-independent quantum yield of the microalgae. This inequality is due to light attenuation within the sample, and is eliminated when attenuation coefficients 


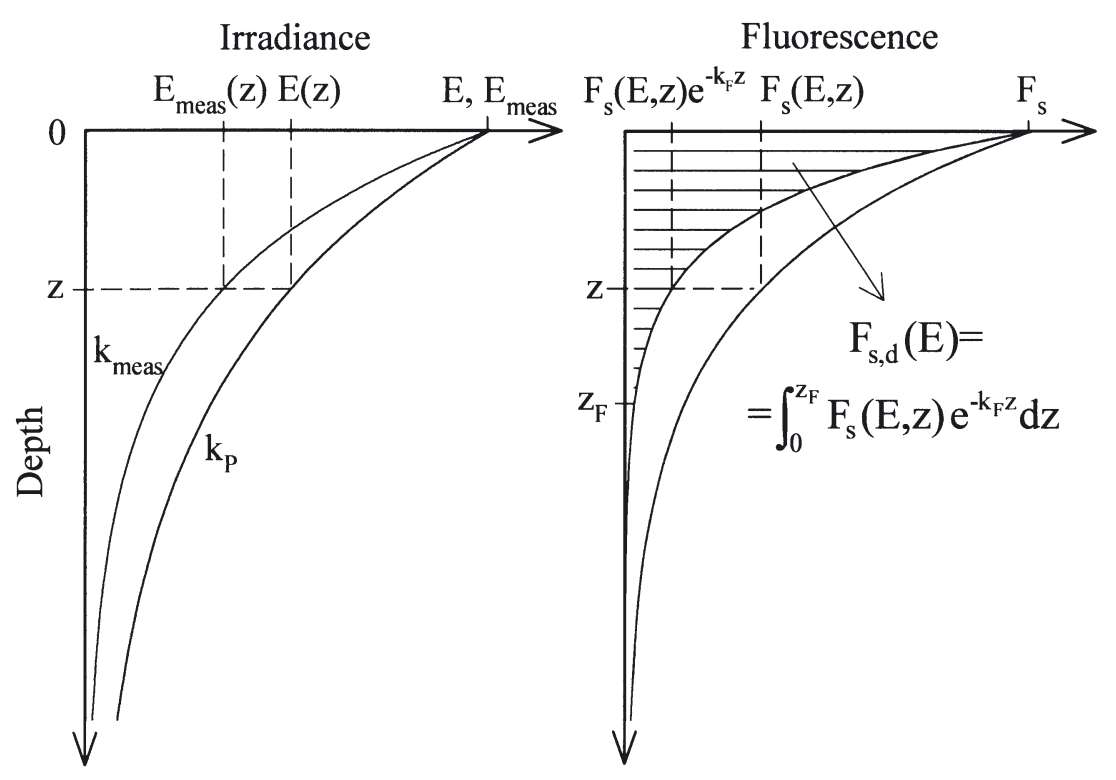

Fig. 1. Illustration of terms used in Eqs. (2) \& (3). Depth-integration fluorescence is determined by the attenuation of downwelling measuring and actinic irradiance, and of upwelling fluorescence. The fluorescence $\left(F_{\mathrm{s}}\right.$ level) emitted at each depth $z$ is induced by the actinic irradiance at $z, E(z)$, which is determined by the attenuation of incident irradiance, $E$, between the surface and depth $z$ (attenuation coefficient $k_{\mathrm{P}}$ ). The measured level of fluorescence emitted at depth $z_{\text {, }}$ $F_{\mathrm{s}}(E, z)$, is determined by the level of measuring irradiance at $z, E_{\text {meas }}(z)$, dependent on the surface level, $E_{\text {meas }}$ and the attenuation coefficient $k_{\text {meas }}$. Due to attenuation of upwelling fluorescence (attenuation coefficient $k_{\mathrm{F}}$ ), only a fraction of the level emitted at depth $z$ is actually measured at the surface (note that $\left.F_{\mathrm{S}}(E, Z)>F_{\mathrm{s}}(E, z) e^{-k_{\mathrm{F} Z}}\right)$

are very low or null: $k_{\text {meas }} \approx k_{\mathrm{P}} \approx k_{\mathrm{F}} \approx 0\left(\mathrm{e}^{-k_{\text {meas }} z} \approx \mathrm{e}^{-k_{\mathrm{P}} z} \approx\right.$ $\left.\mathrm{e}^{-k_{\mathrm{F}} Z} \approx 1\right), F_{\mathrm{s}}(E, z)$ and $F_{\mathrm{m}}{ }^{\prime}(E, z)$ become constant over $z$, and $\Delta F / F_{\mathrm{m}, \mathrm{d}}^{\prime}(E) \approx \Delta F / F_{\mathrm{m}}{ }^{\prime}(E)$ (Eqs. $\left.3 \& 4\right)$.

Numerical simulations. The effects of light attenuation and of depth integration of fluorescence emission on the computation of the effective PSII quantum yield were quantified by comparing light curves of relative electron transport rate (for brevity, ETR) computed from physiological and depth-integrated parameters:

$$
\begin{aligned}
& \operatorname{ETR}(E)=E \Delta F / F_{\mathrm{m}}{ }^{\prime}(E) \\
& E_{T R R_{\mathrm{d}}(E)}=E \Delta F / F_{\mathrm{m},{ }_{\mathrm{d}}(E)}(E)
\end{aligned}
$$

$E T R$ and $E T R_{\mathrm{d}}$ vs $E$ curves were compared for the natural range of variation of the parameters relevant for fluorescence emission (Eqs. $2 \& 3$ ): $F_{\mathrm{s}}$ and $F_{\mathrm{m}}{ }^{\prime}$ vs $E$ curves (measured without the influence of light attenuation or depth integration of fluorescence, thus reflecting solely changes in $\phi F$ ), attenuation coefficients for measuring and actinic light and for emitted fluorescence ( $k_{\text {meas }}, k_{\mathrm{P}}$ and $k_{\mathrm{F}}$ ), and vertical distribution of microalgal biomass, $\operatorname{chl}(z)$; for short-term $(<1$ day) time scales, changes in depth-integrated light absorption can be expected to result mainly from changes in the vertical distribution of microalgal biomass (Serôdio et al. 2001). The depth profiles of $F_{\mathrm{s}}(E, z)$ and $F_{\mathrm{m}}{ }^{\prime}(E, z)$ required to compute $\Delta F / F_{\mathrm{m}, \mathrm{d}}(E)$ and $E T R_{\mathrm{d}}(E)$ were calculated by converting depth-independent $F_{\mathrm{s}}$ and $F_{\mathrm{m}}{ }^{\prime}$ vs $E$ curves into vertical profiles considering an exponential attenuation of $E$ within the sediment. Both measured and published values of the various parameters of Eqs. (2) \& (3) were used for the calculation of $\Delta F / F_{\mathrm{m}}$, d vs $E$ curves. Although only data obtained with the most common PAM fluorometers were used (red LED measuring light source, white light source as actinic and saturating pulses), the rationale and results of the simulations are applicable to more recent models that use blue LEDs as measuring, actinic and saturating light sources. Simulations of depth-integrated fluorescence emission were carried out using MathCad 2001 Pro (MathSoft). Linear interpolation was applied between consecutive values of the $F_{\mathrm{s}}$ and $F_{\mathrm{m}}{ }^{\prime}$ vs $E$ curves. ETR and $E T R_{\mathrm{d}}$ vs $E$ curves were compared using the parameters estimated by fitting the model of Platt et al. (1980): $\alpha$ (initial slope of the curve), $E T R_{\mathrm{m}}$ (maximum value of $E T R$ ), and $\beta$ (photoinhibition parameter). The model was fitted iteratively using Statistica 6.0 (StatSoft).

$\boldsymbol{F}_{\mathrm{s}}$ and $\boldsymbol{F}_{\mathrm{m}}{ }^{\prime}$ vs $\boldsymbol{E}$ curves. $\Delta F / F_{\mathrm{m}}{ }^{\prime}{ }_{\mathrm{d}}$ vs $E$ curves were calculated from $F_{\mathrm{s}}$ and $F_{\mathrm{m}}{ }^{\prime}$ vs $E$ curves measured on samples where light attenuation could be assumed as negligible, using microalgae populations from natural microphytobenthos samples and from diatoms grown in culture. Natural microalgae populations were obtained using the 'lens tissue technique' (William 1963) on undisturbed samples collected during low tide on intertidal mudflats near Vista Alegre, Ria de Aveiro, a mesotidal estuary located on the central west coast of Portugal, in March 2003. The sampling site had fine muddy sediment $(97 \%$ particles $<63 \mu \mathrm{m})$ dominated by diatoms of the genera Navicula, Nitzschia, and Gyrosigma (81.6\% total cell numbers). Cells were collected by placing 2 pieces of lens tissue on the surface of the sample; the tissue was kept exposed and illuminated during the period of low tide for several hours. After microalgae migrated into the lens tissue in sufficient numbers, the upper piece of lens tissue was removed and used for fluorescence measurements (see below) and taxonomic identification. $F_{\mathrm{s}}$ and $F_{\mathrm{m}}{ }^{\prime}$ vs $E$ curves were measured directly on the lens tissue, as 
this allowed to eliminate light attenuation within the sample, obtaining depth-independent measurements.

Suspensions of the benthic diatom Cylindrotheca closterium (Ehrenberg) Lewin et Reinman were also used for the measurement of $F_{\mathrm{s}}$ and $F_{\mathrm{m}}$ 'vs $E$ curves. $C$. closterium was isolated from intertidal sediments of the Ria de Aveiro and grown in unialgal semi-continuous batch cultures at $15{ }^{\circ} \mathrm{C}$ under $50 \mu \mathrm{mol}$ quanta $\mathrm{m}^{-2}$ $\mathrm{s}^{-1}$ in a 12:12 $\mathrm{h}$ light:dark cycle, in natural seawater enriched with f/2 medium (Guillard \& Ryther 1962). Sample concentration was such that light attenuation could be assumed to be negligible $\left(<50 \mu \mathrm{g} \mathrm{chl} \mathrm{a} \mathrm{l}^{-1}\right)$.

In addition to the measured $F_{\mathrm{s}}$ and $F_{\mathrm{m}}{ }^{\prime}$ vs $E$ curves, published data regarding diatom suspensions were also used. Due to the need to calculate the integral of the vertical profile of $F_{\mathrm{s}}$ and $F_{\mathrm{m}}$ ' emissions separately (Eqs. $3 \& 4$ ), only publications that included separate $F_{\mathrm{s}}$ and $F_{\mathrm{m}}{ }^{\prime}$ vs $E$ curves were used (Table 2).

Biomass vertical profiles. Changes in the vertical distribution of microalgae that result from migratory movements are expected to affect the depth-integrated fluorescence emission (Eqs. $2 \& 3$ ). Therefore, $F_{\mathrm{s}, \mathrm{d}}$ and $F_{\mathrm{m}, \mathrm{d}}{ }^{\prime}$ were calculated for extreme profiles chosen to represent the downward migration of micro- algae during high tide or exposure to high irradiances (Profile C1) and the accumulation of microalgae at the surface during diurnal low tide (Profile C2), and these were compared to the case of a homogenous profile (C0). Profiles C1 and C2 were selected from published light-limited rates of photosynthesis measured on undisturbed samples under a wide range of in situ conditions (Serôdio et al. 2001). Similar profiles were reported by de Brouwer \& Stal (2001) and Kelly et al. (2001).

Light attenuation. Calculation of $\Delta F / F_{\mathrm{m}}{ }^{\prime}$ d vs $E$ curves was based on the only published values for attenuation coefficients for measuring and actinic (ambient, PAR) light, and fluorescence emission in muddy sediments $\left(k_{\mathrm{p}}=16.9 \mathrm{~mm}^{-1} ; k_{\text {meas }}+k_{\mathrm{F}}=53.5 \mathrm{~mm}^{-1}\right.$; Serôdio et al. 2001). The importance of light attenuation for the depth integration effect was assessed by calculating $\Delta F / F_{\mathrm{m}, \mathrm{d}}$ vs $E$ curves for $k_{\mathrm{P}}$ values varying between 0 and $22 \mathrm{~mm}^{-1}$ (ca. $+30 \%$ of the reference value; $k_{\text {meas }}+$ $k_{\mathrm{F}}$ was maintained proportional to $k_{\mathrm{P}}$ ), encompassing the range of variation of $k_{\mathrm{P}}$ found for muddy and sandy sediments (Colijn 1982, Baillie 1987, Kühl \& Jørgensen 1994, Kromkamp et al. 1998, Barranguet \& Kromkamp 2000, Underwood 2002).

Table 2. Source and characteristics of the $F_{\mathrm{s}}$ and $F_{\mathrm{m}}{ }^{\prime}$ vs $E$ curves used in the numerical simulations, and variation (\%) in the parameters of the $E T R$ vs $E$ curve caused by depth integration of fluorescence for different microalgal biomass profiles: C0 - homogenous profile; C1, C2 - profiles corresponding to Fig. 4A and 4B, respectively; U - unialgal culture; M - microphytobenthos; $\mathrm{SSC}, \mathrm{RLC}$ - steady state and rapid light curve (time under each light level)

\begin{tabular}{|c|c|c|c|c|c|c|c|}
\hline & Sample and light curves & $\operatorname{chl}(z)$ & $\alpha$ & $E T R_{\mathrm{m}}$ & $E_{\mathrm{k}}$ & $\beta$ & Source \\
\hline Diatoms & M, lens tissue RLC (10 s) & $\begin{array}{l}\mathrm{C} 0 \\
\mathrm{C} 1 \\
\mathrm{C} 2\end{array}$ & $\begin{array}{l}-1.1 \\
-2.0 \\
-1.1\end{array}$ & $\begin{array}{l}41.0 \\
56.8 \\
32.4\end{array}$ & $\begin{array}{l}42.5 \\
60.0 \\
33.8\end{array}$ & $\begin{array}{l}-37.1 \\
-47.3 \\
-21.7\end{array}$ & This study \\
\hline \multirow[t]{3}{*}{$\begin{array}{l}\text { Cylindrotheca } \\
\text { closterium }\end{array}$} & $\begin{array}{l}\mathrm{U}, \mathrm{RLC} \\
(1 \mathrm{~min})\end{array}$ & $\begin{array}{l}\mathrm{C} 0 \\
\mathrm{C} 1 \\
\mathrm{C} 2\end{array}$ & $\begin{array}{l}-3.3 \\
-3.5 \\
-3.0\end{array}$ & $\begin{array}{l}40.4 \\
54.9 \\
32.7\end{array}$ & $\begin{array}{l}45.1 \\
60.5 \\
36.8\end{array}$ & $\begin{array}{r}15.2 \\
-22.8 \\
60.1\end{array}$ & \\
\hline & $\mathrm{U}, \mathrm{SSC}$ & $\begin{array}{l}\mathrm{C} 0 \\
\mathrm{C} 1 \\
\mathrm{C} 2\end{array}$ & $\begin{array}{r}0.3 \\
-0.6 \\
0.4\end{array}$ & $\begin{array}{l}40.6 \\
57.3 \\
32.3\end{array}$ & $\begin{array}{l}40.2 \\
58.3 \\
31.7\end{array}$ & $\begin{array}{l}-65.5 \\
-77.0 \\
-51.7\end{array}$ & \\
\hline & $\begin{array}{l}\mathrm{U}, \mathrm{RLC} \\
(1 \mathrm{~min})\end{array}$ & $\begin{array}{l}\mathrm{C} 0 \\
\mathrm{C} 1 \\
\mathrm{C} 2\end{array}$ & $\begin{array}{l}-1.6 \\
-2.3 \\
-1.6\end{array}$ & $\begin{array}{l}39.9 \\
54.8 \\
31.9\end{array}$ & $\begin{array}{l}42.2 \\
58.3 \\
34.0\end{array}$ & $\begin{array}{l}-45.0 \\
-55.0 \\
-27.5\end{array}$ & \\
\hline \multirow[t]{4}{*}{$\begin{array}{l}\text { Phaeodactylum } \\
\text { tricornutum }\end{array}$} & $\begin{array}{c}\text { U, SSC } \\
(5-10 \mathrm{~min})\end{array}$ & $\begin{array}{l}\mathrm{C} 0 \\
\mathrm{C} 1 \\
\mathrm{C} 2\end{array}$ & $\begin{array}{l}-6.8 \\
-8.2 \\
-6.0\end{array}$ & $\begin{array}{l}55.3 \\
75.8 \\
44.7\end{array}$ & $\begin{array}{l}66.7 \\
91.5 \\
53.9\end{array}$ & $\begin{array}{l}-73.8 \\
-71.8 \\
-50.3\end{array}$ & Geel et al. (1997) \\
\hline & $\begin{array}{c}\mathrm{U}, \mathrm{SSC} \\
(2-4 \mathrm{~min})\end{array}$ & $\begin{array}{l}\mathrm{C} 0 \\
\mathrm{C} 1 \\
\mathrm{C} 2\end{array}$ & $\begin{array}{l}-8.3 \\
-9.0 \\
-6.7\end{array}$ & $\begin{array}{l}56.9 \\
76.4 \\
43.8\end{array}$ & $\begin{array}{l}71.2 \\
93.9 \\
54.1\end{array}$ & $\begin{array}{l}- \\
- \\
-\end{array}$ & Flameling \& Kromkamp (1998) \\
\hline & $\mathrm{U}, \mathrm{SSC}$ & $\begin{array}{l}\mathrm{C} 0 \\
\mathrm{C} 1 \\
\mathrm{C} 2\end{array}$ & $\begin{array}{l}4.9 \\
6.0 \\
5.3\end{array}$ & $\begin{array}{l}45.5 \\
63.4 \\
32.7\end{array}$ & $\begin{array}{l}38.7 \\
54.2 \\
26.0\end{array}$ & $\begin{array}{l}- \\
- \\
-\end{array}$ & Serôdio et al. (2001) \\
\hline & Overall & $\begin{array}{l}\mathrm{C} 0 \\
\mathrm{C} 1 \\
\mathrm{C} 2\end{array}$ & $\begin{array}{l}-2.3 \\
-2.8 \\
-1.8\end{array}$ & $\begin{array}{l}45.7 \\
63.3 \\
35.8\end{array}$ & $\begin{array}{l}49.5 \\
68.1 \\
38.6\end{array}$ & $\begin{array}{l}-41.2 \\
-54.8 \\
-18.2\end{array}$ & \\
\hline
\end{tabular}


Experimental comparison between $E T R$ and $E T R_{\mathrm{d}} \mathrm{vs}$ $\boldsymbol{E}$ curves. The effects of the calculation of $\Delta F / F_{\mathrm{m}}{ }^{\prime}$ and $E T R$ from depth-integrated parameters were experimentally confirmed by comparing fluorescence light curves measured on samples where light attenuation was negligible (lens tissue with harvested microalgae, as described above; $\Delta F / F_{\mathrm{m}}{ }^{\prime}$ and $E T R$ vs $E$ curves) and on intact sediment samples $\left(\Delta F / F_{\mathrm{m}, \mathrm{d}}{ }^{\prime}\right.$ and $E T R_{\mathrm{d}}$ vs $E$ curves). Measurements on undisturbed sediment samples and on lens tissues were carried out by positioning the fluorometer's fiberoptics (see below) perpendicularly to the sample surface at a constant distance of $1 \mathrm{~mm}$ with the help of a micromanipulator (MM33, Märtzhäuser). Measurements on lens tissues were carried out by placing the lens tissue on a microscope slide, where it was kept wet until the measurements were completed. The area of the microscope slide containing the lens tissue was held at some distance from other surfaces, so that fluorescence could be measured without receiving any background signals. To reduce the effects of factors other than light attenuation, all samples were collected at the same time and sampling location. All other experimental conditions (fiber diameter, distance to sample, duration of light curve, fluorometer settings) were the same for the 2 sets of measurements.

Published $\Delta F / F_{\mathrm{m}}{ }^{\prime}$ and $\Delta F / F_{\mathrm{m},{ }^{\prime}}$ vs $E$ curves, measured on diatom suspensions and on undisturbed microphytobenthos samples, respectively, were also compared. In studies with more than 2 curves, only the 2 curves exhibiting the highest and lowest values were considered. ETR and $E T R_{\mathrm{d}}$ values were calculated by applying Eqs. (5) \& (6) to $\Delta F / F_{\mathrm{m}}{ }^{\prime}$ and $\Delta F / F_{\mathrm{m},{ }^{\prime} \mathrm{d}}$ values, respectively.

Fluorescence measurements. Chlorophyll a fluorescence was measured using a PAM fluorometer comprising a computer-operated PAM-CONTROL Universal Control Unit (Walz) and a new type of emitter-detector unit, the WATER-EDF-Universal (Gademann Instruments), which provides the possibility of using fiberoptics of different diameters (e.g. $6 \mathrm{~mm}, 1.5 \mathrm{~mm}$ and $100 \mu \mathrm{m}$ ) and uses a modulated blue light (Luxeon Star 5W LED-lamp peaking at $450 \mathrm{~nm}$, half-bandwidth of $20 \mathrm{~nm}$ ) as source for measuring, actinic and saturating light. By using a photomultiplier fluorescence detector (Photosensor Module H-6779-01, Hamamatsu) to detect emitted fluorescence, it becomes possible to measure very dilute samples

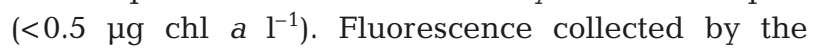
fiberoptics is filtered by a $45^{\circ}$ dichroic beamsplitter (passing $\cong \lambda>600 \mathrm{~nm}$ ), collimated by a $12 \mathrm{~mm}$ spherical lens, and focused via a 4 mm RG 645 filter (Schott) on a pin hole diaphragm in front of the photomultiplier. Fluorescence emission was induced by modulated light emitted at a frequency of $18 \mathrm{~Hz}$ when measuring
$F_{0}$, or $20 \mathrm{kHz}$ when measuring other parameters. Measurements on undisturbed sediment samples and on lens tissues were carried out using a $1.5 \mathrm{~mm}$ diameter plastic fiber, while measurements on suspensions were carried out using a $6 \mathrm{~mm}$ diameter fluid light guide, connected to a fluorescence cuvette (KS-101, Walz) by a special adaptor.

In order to increase the range of variability in the shape of the $F_{\mathrm{s}}$ and $F_{\mathrm{m}}$ ' vs $E$ curves used in the simulations, light curves were measured applying different exposure periods under each light level: $10 \mathrm{~s}$ or $1 \mathrm{~min}$ (rapid light curves, RLC), or the time required for reaching a new steady state after each change in light level, usually between 2 and 5 min (steady-state light curves, SSC). To minimize the effects of microalgae migration during the construction of the light curve, RLCs were applied when working on intact sediment samples.

\section{RESULTS}

\section{Effects on light curves}

The general effects on the determination of effective PSII quantum yield and of ETR vs $E$ curves from depthintegrated fluorescence measurements, as derived from numerical simulations, are illustrated in Fig. 2. As $F_{\mathrm{m}}{ }^{\prime}$ decreases steeply with $E$ (Fig. 2A), fluorescence stimulated by lower irradiances at layers below the surface is comparatively higher than that emitted at the surface. The contribution of these deeper layers to the depth-integrated fluorescence signal reduces the rate of decrease of $F_{\mathrm{m}, \mathrm{d}}{ }^{\prime}$ with $E$, in comparison with the physiological response of the algae (Fig. 2A). In the case of $F_{S}$ these effects cause $F_{\mathrm{S}, \mathrm{d}}$ to remain lower than $F_{S}$ for most of the range of $E$ (Fig. 2B). As a result, the overall effect is an increase in variable fluorescence $\left(F_{\mathrm{m}, \mathrm{d}}{ }^{\prime}-F_{\mathrm{s}, \mathrm{d}}>F_{\mathrm{m}}{ }^{\prime}-F_{\mathrm{s}}\right.$ Fig. 2A,B) and, consequently, estimates of PSII quantum yield or relative electron transport based on depth-integrated parameters become higher than the corresponding physiological values (Fig. 2C,D). Moreover, the magnitude of this overestimation increases monotonously with $E$, reducing the overall range of variation of depth-integrated measurements. In the particular case of $E=0, \Delta F / F_{\mathrm{m}}{ }^{\prime}{ }^{\mathrm{d}}$ and $\Delta F / F_{\mathrm{m}}{ }^{\prime}$ are expected to be identical because $F_{0}$ and $F_{\mathrm{m}}$ emissions are constant over depth, and Eqs. (2) \& (4) become equivalent.

The determination of ETR vs E curves from depthintegrated measurements is additionally complicated by the fact that, by multiplying $\Delta F / F_{\mathrm{m}}{ }^{\prime}$ by $E$ (Eqs. $5 \& 6$ ), the overestimation is amplified. Furthermore, because this bias increases with $E$, the different parameters of the ETR vs $E$ curve are differently affected by the depth integration of fluorescence parameters, as illus- 


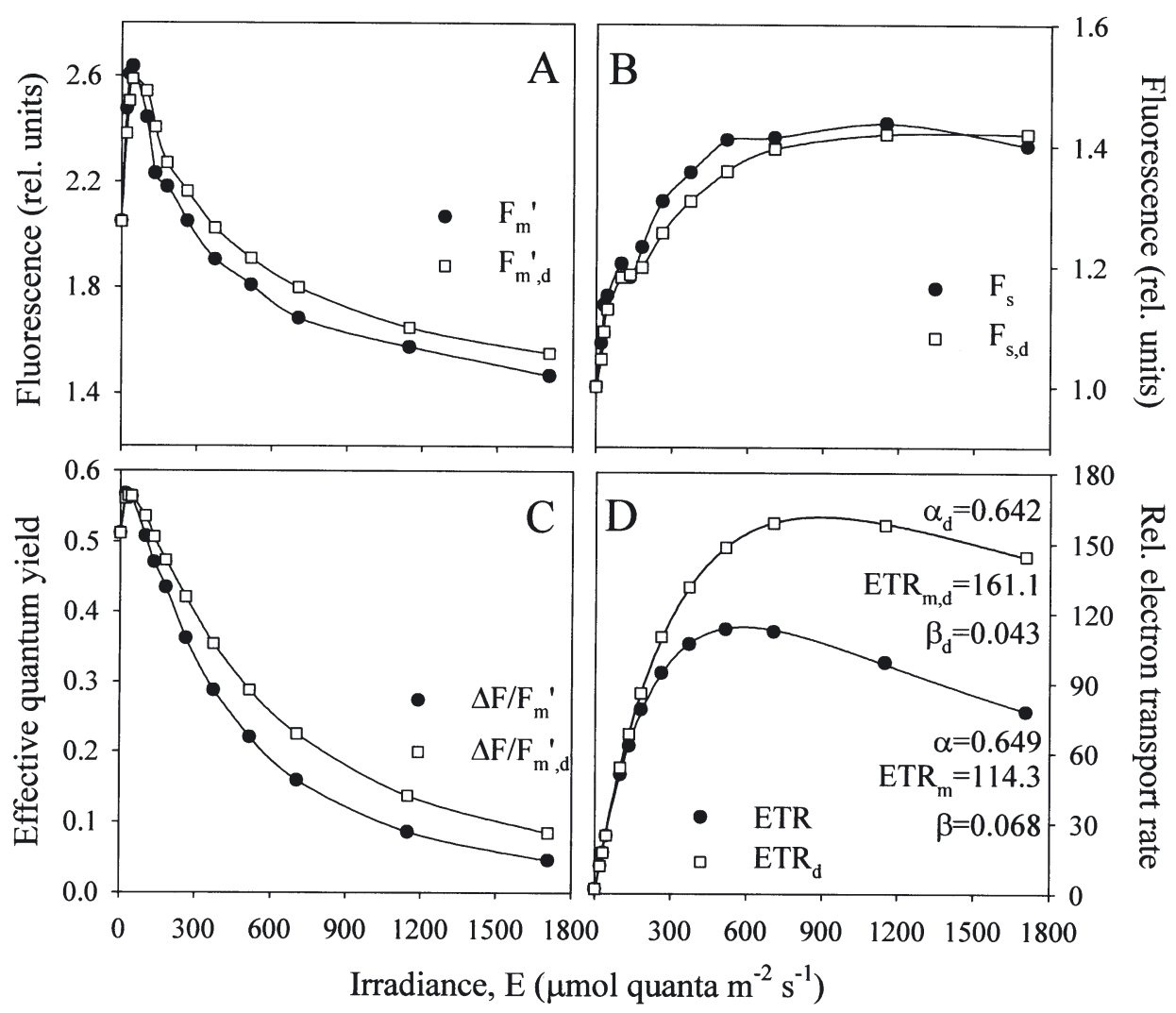

Fig. 2. General effects of depth integration of fluorescence parameters and implications for light curves. Due to the variation of $F_{\mathrm{s}}$

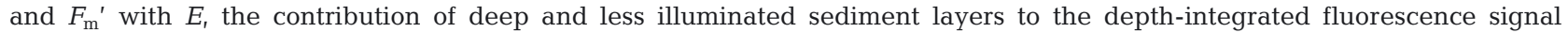
attenuates the variation of depth-integrated levels $F_{\mathrm{s}, \mathrm{d}}$ and $F_{\mathrm{m}, \mathrm{d}}{ }^{\prime}$ with $E(\mathrm{~A})$. As a consequence, variable fluorescence is increased $\left(F_{\mathrm{m}, \mathrm{d}}{ }^{\prime}-F_{\mathrm{s}, \mathrm{d}}>F_{\mathrm{m}}{ }^{\prime}-F_{\mathrm{s}}\right)(\mathrm{A}, \mathrm{B})$ and estimates of effective PSII quantum yield or relative electron transport rate overestimate the physiological values $\left(\Delta F / F_{\mathrm{m}, \mathrm{d}}{ }^{\prime}>\Delta F / F_{\mathrm{m}}{ }^{\prime}\right.$ and $\left.E T R_{\mathrm{d}}>E T R\right)(\mathrm{C}, \mathrm{D})$. These effects increase with irradiance level, affecting the parameters of the $E T R_{\mathrm{d}}$ vs $E$ curve related to light saturation and photoinhibition $\left(E T R_{\mathrm{m}, \mathrm{d}}, E_{\mathrm{k},} \beta\right)$ but not the parameter describing light limitation $\left(\alpha_{\mathrm{d}}\right)$. Fluorescence levels are mean of 3 replicates, normalised to $F_{\mathrm{s}}(0)$ or $F_{\mathrm{s}, \mathrm{d}}(0)$

trated in Fig. 2D: while $\alpha$, the initial slope of the curve, shows little variation (a small decrease of $1.1 \%$; Table 2), the maximum ETR value, $E T R_{\mathrm{m}}$, is strongly overestimated $(41.0 \%)$. The different effects on $\alpha$ and $E T R_{\mathrm{m}}$ affect the determination of the light saturation parameter $E_{\mathrm{k}}$, which is overestimated by $42.5 \%$. Moreover, the overall shape of the curve is substantially affected: while the ETR vs $E$ curve exhibits a clear photoinhibition pattern, with values decreasing above $500 \mu \mathrm{mol}$ quanta $\mathrm{m}^{-2} \mathrm{~s}^{-1}$, this pattern is almost eliminated in the $E T R_{\mathrm{d}}$ vs $E$ curve, where the photoinhibition parameter $\beta$ is reduced by $37.1 \%$.

\section{$F_{\mathrm{s}}$ and $F_{\mathrm{m}}^{\prime}$ vs $E$ curves}

To assess the importance of the shape of the $F_{\mathrm{s}}$ and $F_{\mathrm{m}}{ }^{\prime}$ vs $E$ curves on the effects described above, $\Delta F / F_{\mathrm{m}}{ }^{\prime}$ d and $E T R_{\mathrm{d}}$ vs $E$ curves were calculated for a range of $F_{\mathrm{s}}$ and $F_{\mathrm{m}}^{\prime}$ vs $E$ curves obtained from measurements made under a wide range of conditions and from pub- lished data sets (Table 2). As illustrated in Fig. 3, the results are largely independent of the shape of the $F_{\mathrm{s}}$ and $F_{\mathrm{m}}{ }^{\prime}$ vs $E$ curves, and similar to the ones described above: undisturbed sediment samples may show little or no photoinhibitory pattern, in spite of being composed of microalgae that are photoinhibited under moderate irradiances (Fig. 3A,B); or, samples of microalgae showing light saturation may apparently not saturate (Fig. 3C). On average (considering all data sets), light curves computed from depth-integrated parameters showed a slight reduction in $\alpha(-2.3 \%)$, a large increase in $E T R_{\mathrm{m}}$ and $E_{\mathrm{k}}(45.7 \%$ and $49.5 \%)$, and a large decrease in $\beta(-41.2 \%)$.

\section{Vertical profiles of biomass}

Biomass profiles with a subsurface maximum (Profile $\mathrm{C} 1$ ) increase the relative weight of deeper layers in terms of the contribution to depth-integrated fluorescence detected at the surface, therefore magnifying 


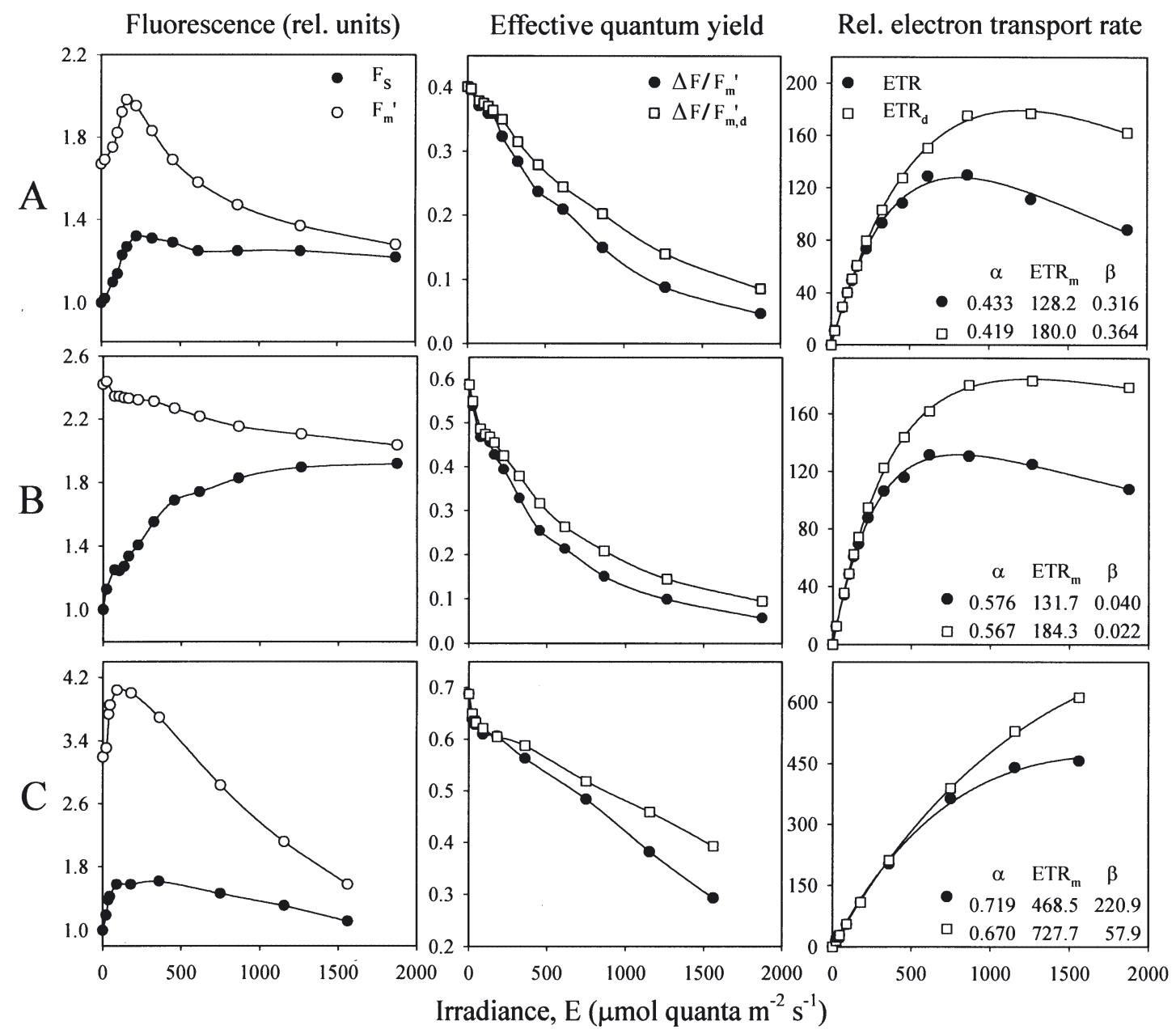

Fig. 3. Use of depth-integrated parameters on $\Delta F / F_{\mathrm{m}}{ }^{\prime}$ and $E T R$ for different $F_{\mathrm{s}}$ and $F_{\mathrm{m}}{ }^{\prime}$ vs $E$ curves. (A,B) Cylindrotheca closterium culture, rapid light curve $(1 \mathrm{~min})$. (C) Phaeodactylum tricornutum culture, steady-state light curve (after Geel et al. 1997). Fluorescence levels are normalised to $F_{\mathrm{s}}(0)$ or $F_{\mathrm{s}, \mathrm{d}}(0)$

the biases described above. As exemplified in Fig. 4, Profile $\mathrm{C} 1$ attenuates the vertical decrease in $F_{\mathrm{s}}$ and $F_{\mathrm{m}}{ }^{\prime}$ emissions, increasing the importance of light attenuation and the difference between $E T R$ and $E T R_{\mathrm{d}}$ vs $E$ curves. Most differences concern the light-saturated part of the curve: on average, changes in $\alpha$ are small and inconsistent, but the differences in $E T R_{\mathrm{m}}$ and $E_{\mathrm{k}}$ increase to $62.8 \%$ and $68.1 \%$, respectively. Also the decrease in the photoinhibition parameter $\beta$ is generally enhanced, representing a greater reduction of the photoinhibitory pattern exhibited in the ETR vs E curves. Conversely, the accumulation of biomass at the surface (Profile C2, Fig. 4 C), by increasing the relative contribution of surface layers to the depth-integrated fluorescence, leads to a reduction of the effects associated with depth integration: the overestimations of $E T R_{\mathrm{m}}$ and $E_{\mathrm{k}}$ are reduced (to $35.8 \%$ and $38.6 \%$, respectively) and the underestimation of $\beta$ is generally smaller.

\section{Light attenuation}

The attenuation of measuring and ambient light within the sediment affects the difference between $E T R$ and $E T R_{\mathrm{d}}$ vs $E$ curves, as this difference increases non-linearly with light attenuation. While $\alpha$ is hardly affected, large variations in $E T R_{\mathrm{m}, \mathrm{d}}$ and $\beta_{\mathrm{d}}$ occur for $k_{\mathrm{p}}$ $<15 \mathrm{~mm}^{-1}$ (Fig. 5), so that substantial overall effects are expected even for sandy sediments: for $k_{\mathrm{p}}=5 \mathrm{~mm}^{-1}$, changes in $E T R_{\mathrm{m}}$ and $\beta$ attain ca. $20 \%$ and $-15 \%$, respectively.

\section{Experimental comparison between $E T R$ and $E T R_{\mathrm{d}}$ vs $E$ curves}

The results of numerical simulations were generally confirmed experimentally. As predicted for moderate and high irradiances, variable fluorescence is higher 
in samples with strong light attenuation (sediment) than in optically thin samples (lens tissue), or $F_{\mathrm{s}, \mathrm{d}}<F_{\mathrm{s}}$ and $F_{\mathrm{m}, \mathrm{d}}^{\prime}>F_{\mathrm{m}}{ }^{\prime}$ (Fig. 6A), causing an apparent increase in relative electron transport rate $\left(E T R_{\mathrm{d}}>E T R_{;}\right.$ Fig. 6B). The difference between $E T R_{\mathrm{d}}$ and $E T R$ vs $E$ curves was actually higher than that predicted by applying the simulation model on the $F_{\mathrm{s}}$ and $F_{\mathrm{m}}{ }^{\prime}$ measurements made on the lens tissue (Fig. 6B). However, most of the difference between predicted and observed curves can be eliminated $\left(\mathrm{p}<0.001, \mathrm{r}^{2}=\right.$ 0.997 ) by increasing the value of the attenuation coefficient for the actinic light, which is expected to be

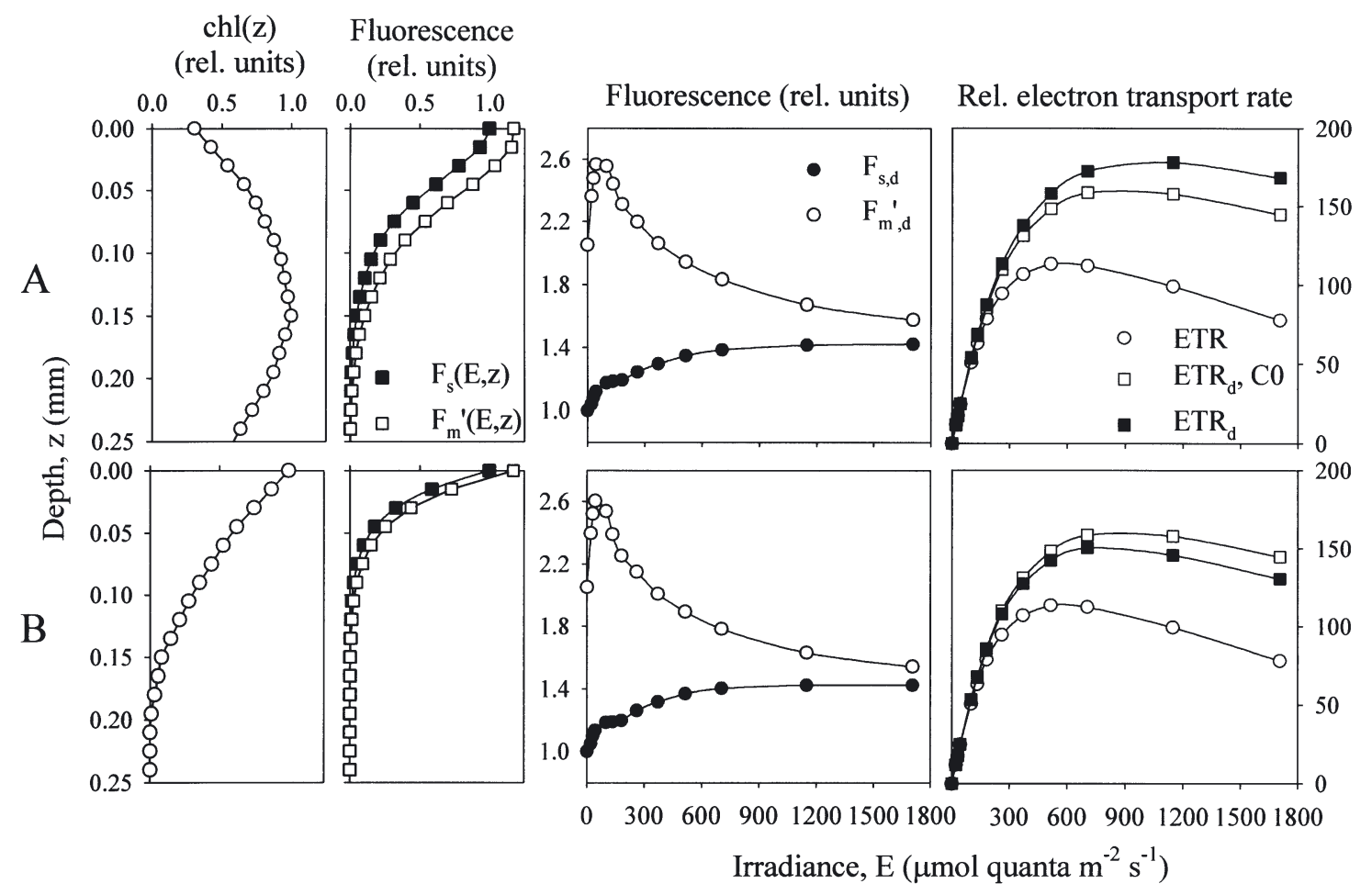

Fig. 4. Effects of vertical distribution of microalgal biomass, $\operatorname{chl}(z)$, on the profiles of fluorescence emission, $F_{\mathrm{s}}(E, z)$ and $F_{\mathrm{m}}{ }^{\prime}(E, z)$, and on the construction of fluorescence light curves from depth-integrated parameters, as compared to the case of homogeneous photic zone $(\mathrm{C} 0)$. (A) Biomass profile ( $\mathrm{C} 1$, Table 2) with a subsurface maximum resulting from downward migration of microalgae. (B) Biomass profile describing accumulation at the surface resulting from upward migration of microalgae (C2, Table 2).

Fluorescence levels are normalised to $F_{\mathrm{s}}(0)$ or $F_{\mathrm{s}, \mathrm{d}}(0)$

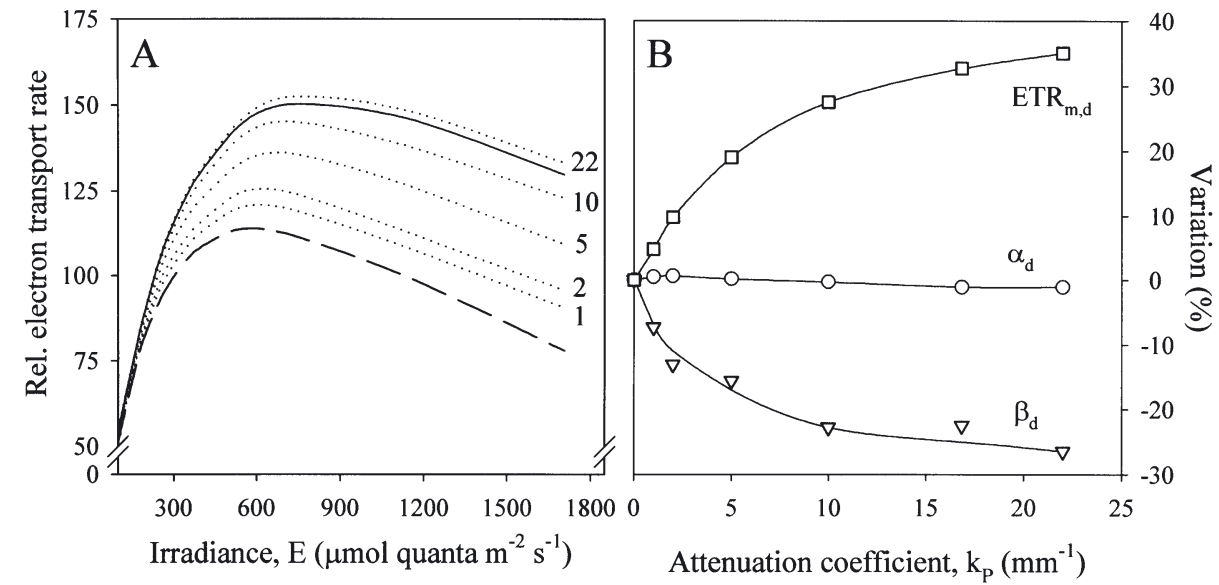

Fig. 5. Effects of changes in light attenuation coefficient $k_{\mathrm{P}}\left(k_{\text {meas }}+k_{\mathrm{F}}\right.$ varying proportionally) on (A) $E T R_{\mathrm{d}}$ vs $E$ curves, and (B) light curve parameters $\alpha_{\mathrm{d}}, E T R_{\mathrm{d}}$ and $\beta_{\mathrm{d}}$. Simulations based on Profile C2. Numbers represent $k_{\mathrm{P}}$ values, and dashed and solid curves represent results for $k_{\mathrm{p}}=0$ and $16.9 \mathrm{~mm}^{-1}$, respectively 


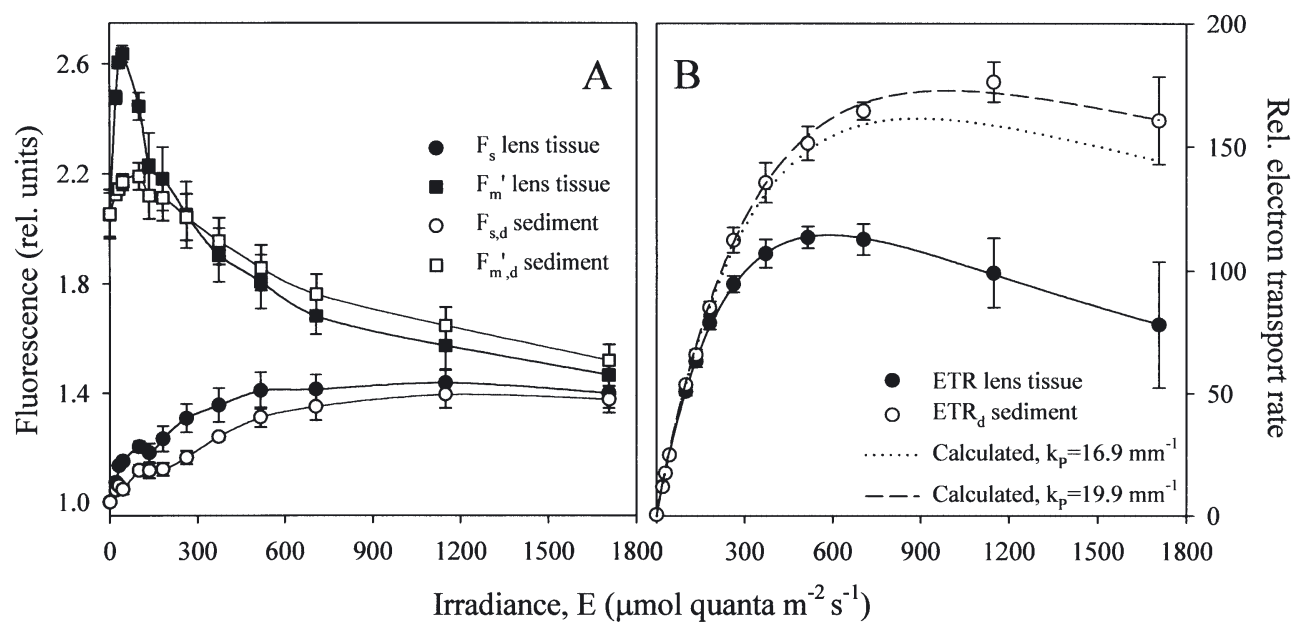

Fig. 6. Experimental verification of effects associated with the use of depth integration of fluorescence parameters. (A) Effects on the $F_{\mathrm{s}}$ and $F_{\mathrm{m}}{ }^{\prime}$ vs $E$ curves. (B) Comparison between measured and calculated $E T R_{\mathrm{d}}$ vs $E$ curves, using the value of attenuation coefficient $k_{\mathrm{P}}$ used in all numerical simulations $\left(k_{\mathrm{p}}=16.9 \mathrm{~mm}^{-1}\right)$, and the value that yielded best fitting $\left(k_{\mathrm{p}}=19.9 \mathrm{~mm}^{-1}\right)$. Fluorescence levels are normalised to $F_{\mathrm{s}}(0)$ or $F_{\mathrm{s}, \mathrm{d}}(0)$. Error bars represent $1 \mathrm{SD}(\mathrm{n}=3)$

higher for the modulated actinic blue light delivered by the fluorometer.

Also published $\Delta F / F_{\mathrm{m}}{ }^{\prime}$ vs $E$ curves reveal a clear difference between measurements made on microalgal suspensions and on intact microphytobenthos samples (Fig. 7). In general, ETR measured on sediment and on suspensions generally coincided under low irradiance levels, but differed with increasing irradiance. Notable differences occur for $E>500 \mu \mathrm{mol}$ quanta $\mathrm{m}^{-2} \mathrm{~s}^{-1}$ : most ETR measurements made on sediments are higher than 250, and most observations on suspensions remain below this value. Of particular interest are the results of Oxborough et al. (2000), who measured $\Delta F / F_{\mathrm{m}}{ }^{\prime}$ on individual microalgae at the sediment surface: although measured on intact sediment samples, the values are clearly similar to the values observed in suspensions.

\section{DISCUSSION}

The application of chlorophyll a fluorescence quenching analysis to microphytobenthos communities has been based on the generally unquestioned assumption that the measurements of $\Delta F / F_{\mathrm{m}}{ }^{\prime}$ made on undisturbed samples reflected exclusively the physiological characteristics of the microalgae present in the sediment. As such, it has been implicitly assumed that these measurements were biomass-independent estimates of the effective PSII quantum efficiency of microalgae and that measurements made on sediments with different optical properties or on suspensions were equivalent and directly comparable. The results of this study indicate that measurements of PSII quantum yield on intact microphytobenthos assemblages are strongly affected by the combined effects of vertical attenuation of actinic light and emitted fluorescence, of depth integration of fluorescence emission, and of vertical distribution of microalgal biomass. Estimates of $\Delta F / F_{\mathrm{m}}$ ' computed from depth-integrated fluorescence measurements do not represent the physiology of the microalgae alone, but are further influenced by the optical characteristics of the sediment. Thus, although $\Delta F / F_{\mathrm{m}}$, d measurements may be of interest when comparing samples of sediments with similar optical characteristics, they are not directly comparable to measurements made on samples of algal suspensions, such as laboratory cultures or field samples of phytoplankton, or microphytobenthos in sediments with different light attenuation properties.

\section{Fluorescence light curves}

The present results have several implications regarding the use of fluorescence light curves to characterise the photophysiological light response of microphytobenthos samples. A direct consequence of the computation of light curves based on depth-integrated measurements is an apparent reduction of the range of variation of the light response of $\Delta F / F_{\mathrm{m}}{ }^{\prime} \mathrm{d}$ or $E T R_{\mathrm{d}}$ caused by the limitation of the decrease of $\Delta F / F_{\mathrm{m}}{ }^{\prime}$ d under high irradiance levels. Besides making it difficult to compare directly with values measured under low light-attenuation conditions, this further complicates the interpretation of the physiological meaning of the absolute value of $\Delta F / F_{\mathrm{m}}{ }^{\prime}{ }_{\mathrm{d}}$ or $E T R_{\mathrm{d}}$, namely in the context of its use for the measurement of electron transport rates through PSII, 


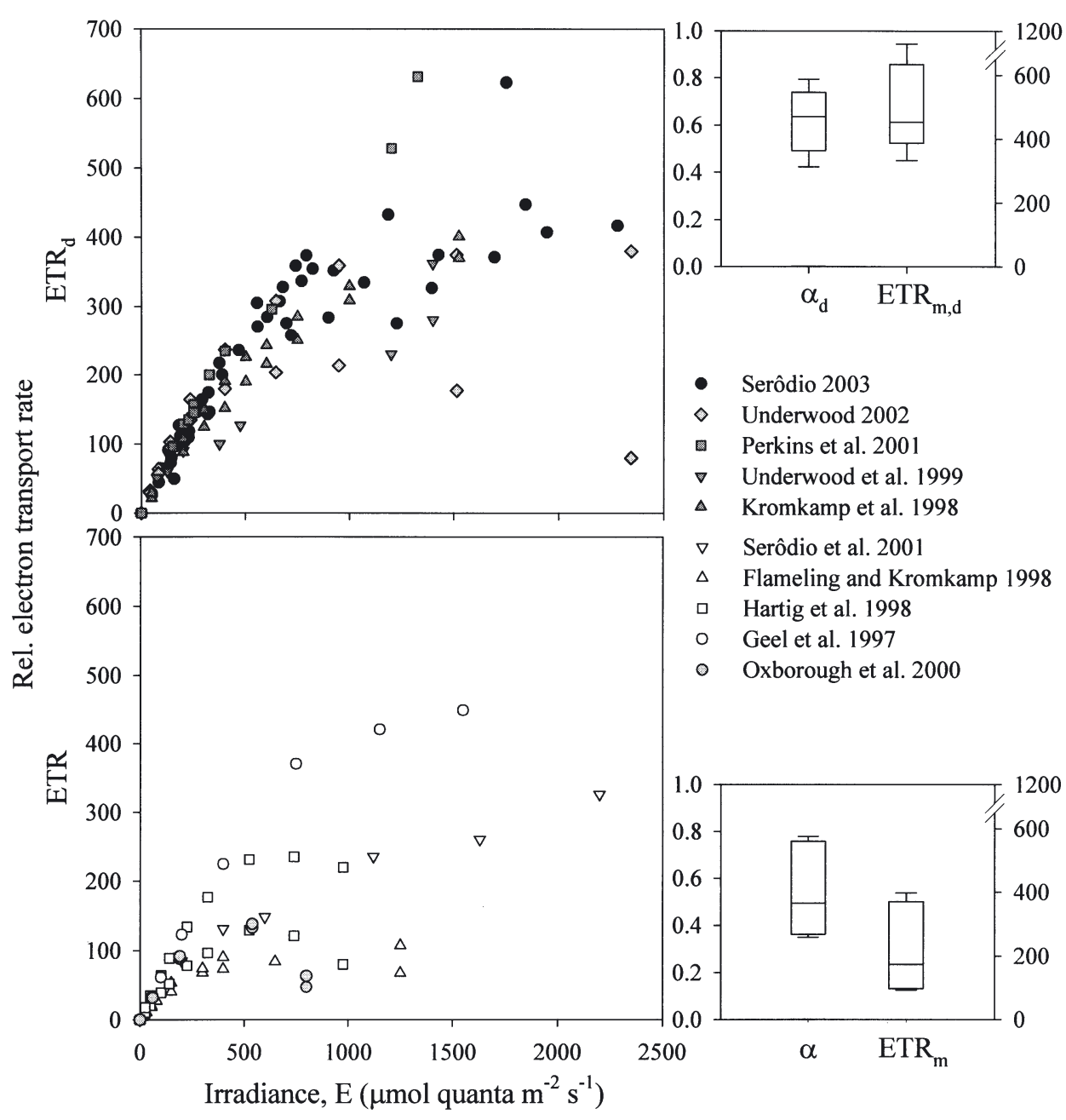

Fig. 7. $E T R_{\mathrm{d}}$ and $E T R$ vs $E$ curves. $E T R_{\mathrm{d}}$ vs $E$ curves were measured on intact microphytobenthos samples composed of diatoms (Kromkamp et al. 1998, Perkins et al. 2001, Serôdio 2003), diatoms and euglenophytes (Underwood 2002), or the diatom Gyrosigma balticum (Underwood et al. 1999). ETR vs E curves were measured on Phaeodactylum tricornutum suspensions (Geel et al. 1997, Flameling \& Kromkamp 1998, Serôdio et al. 2001), resuspended microphytobenthos (Hartig et al. 1998), or on individual diatom and euglenophyte cells on intact microphytobenthos samples (Oxborough et al. 2000). Box plots: median, 25/75 and 10/90 percentiles of light curve parameters

and its relation to the estimation of gross photosynthetic rates (Barranguet \& Kromkamp 2000, Kühl et al. 2001, Serôdio 2003).

Because of the overestimation of ETR $R_{\mathrm{m}}$ but not of $\alpha_{\mathrm{d}}$, intact microphytobenthos samples may appear to be acclimated to higher irradiances than the microalgae that compose the sample are actually acclimated to, by saturating at higher irradiances (higher $E_{\mathrm{k}}$ ) or by appearing less sensitive to photoinhibition (lower $\beta$ ). Furthermore, as $E_{\mathrm{k}, \mathrm{d}}$ depends on light attenuation, microphytobenthos inhabiting finer sediments may appear acclimated to higher irradiance levels. This is thus likely to confound the direct comparison of the light acclimation status of microphytobenthos based on $E_{\mathrm{k}}$, which has been frequently done, both over time (Kromkamp et al. 1998, Defew et al. 2002) or over sam- pling locations having markedly different optical characteristics (Barranguet \& Kromkamp 2000, Underwood 2002).

Fluorescence indices used to characterise the distribution of absorbed light energy to electron charge separation at the PSII reaction centers and to alternative dissipative pathways (photochemical and non-photochemical quenching coefficients, $q_{\mathrm{P}}$ and $q_{\mathrm{N}}$ Schreiber et al. 1986) can also be affected if calculated on the basis of depth-integrated parameters. As with ETR, $q_{\mathrm{P}}$ is will be overestimated in intact sediment samples, and this overestimation will increase with E. Conversely, $q_{\mathrm{N}}$ will be underestimated, suggesting a reduced importance of non-photochemical energy dissipation in microphytobenthos when compared to other microalgal communities (e.g. phytoplankton). 


\section{Vertical migration}

Another result of this study concerns the possibility that variations in the $\Delta F / F_{\mathrm{m}}{ }^{\prime}$ d vs $E$ curve (or under constant irradiance) may be observed independently of changes in the physiological status of the microalgae, due to variations in the vertical distribution of microalgal biomass or in the light attenuation properties of the assemblage. This possibility has been acknowledged implicitly before, when recognizing that the downward migration of microalgae, which reduces the light levels to which cells are exposed, could cause the increase of $\Delta F / F_{\mathrm{m}}{ }^{\prime}$ d under constant irradiance (Underwood et al. 1999, Perkins et al. 2001, 2002). Nonetheless, it has been generally assumed that fluorescence could be used to monitor separately the 2 main processes causing short-term variability in microphytobenthic photosynthesis (Serôdio 2003): (1) physiologically-based changes in the quantum yield of photosynthesis, followed through $\Delta F / F_{\mathrm{m}}{ }^{\prime}$ d (Kromkamp et al. 1998), and (2) vertical migrations, followed through $F_{0}$ or other parameters related to chlorophyll concentration (Serôdio et al. 1997). In opposition to this assumption, the present results show that vertical migration may affect not only the biomass-related fluorescence parameters, but also indices based on ratios of depth-integrated parameters, such as $\Delta F / F_{\mathrm{m}}{ }^{\prime}$ d .

These results have implications on the interpretation of the patterns of variation of fluorescence parameters and indices measured on intact samples. One example is the case of the experiment described by Kromkamp et al. (1998), in which a sediment sample kept under high irradiance levels $\left(800 \mu \mathrm{mol}\right.$ quanta $\left.\mathrm{m}^{-2} \mathrm{~s}^{-1}\right)$ exhibited an increase in both $F_{\mathrm{s}, \mathrm{d}}$ and $F_{\mathrm{m}, \mathrm{d}}{ }^{\prime}$ (confirmed independently to represent the upward migration of microalgae) and $\Delta F / F_{\mathrm{m}, \mathrm{d}}{ }^{\prime}$. Because an increase in $\Delta F / F_{\mathrm{m}, \text { d }}$ during upward migration was not expected considering only the unavoidable decrease of $\Delta F / F_{\mathrm{m}}{ }^{\prime}$ with increasing $E$ (that cells migrating to the surface would experience), a 'micromigration hypothesis' was put forward to explain these observations: a process by which the microalgae near the surface were continuously replaced by others from deeper layers, assumed to be in better physiological condition (Kromkamp et al. 1998). The results on the effects of vertical migration on $\Delta F / F_{\mathrm{m},}{ }^{\prime} \mathrm{d}$, although not excluding the micromigration hypothesis, provide an alternative, simpler explanation to such observations. As exemplified in Fig. 8 , it is possible that an increase in $\Delta F / F_{\mathrm{m}}{ }^{\prime}$, is observed during the accumulation of microalgae in the photic zone (increase in $F_{\mathrm{s}, \mathrm{d}}$ and $F_{\mathrm{m}, \mathrm{d}}{ }^{\prime}$ ) simply due to the vertical redistribution of the same cell population, without any change in the $\Delta F / F_{\mathrm{m}}$ ' vs $E$ response of the microalgae. One possibility is that while overall upward migration occurs, causing an increase of the absolute values of $F_{\mathrm{s}, \mathrm{d}}$ and $F_{\mathrm{m}, \mathrm{d}}{ }^{\prime}$, a subsurface maximum of microalgal accumulation forms. This corresponds to the behaviour attributed to benthic motile diatoms for avoiding exposure to excessive light levels, and is often observed under such conditions (Perkins et al. 2001, 2002, Serôdio 2003).

The results on the effects of vertical migration have consequences for the construction and interpretation of fluorescence light curves. If the time taken to construct a light curve allows for appreciable downward migration of microalgae in response to increasing light levels, the $\Delta F / F_{\mathrm{m}}{ }^{\prime} \mathrm{d}$ values of the light-saturated part of the curve will tend to be higher than is expected for physiological reasons alone. As a consequence, undisturbed samples may appear to be less affected by light-saturation and photoinhibition, and $E T R_{\mathrm{d}}$ vs $E$ curves may exhibit unexpected inflexions in its lightsaturation trend, as reported by Perkins et al. (2001).

\section{Variation during low tide}

The effects associated to the use of depth-integrated fluorescence parameters are also likely to confound the interpretation of time series of $\Delta F / F_{\mathrm{m}}{ }^{\prime} \mathrm{d}$ measurements made in situ during low tide: (1) As the difference between $\Delta F / F_{\mathrm{m}}{ }^{\prime}$ and $\Delta F / F_{\mathrm{m}, \mathrm{d}}{ }^{\prime}$ increases with $E_{\text {, }}$ the overestimation of $\Delta F / F_{\mathrm{m}}$ ' is expected to vary during the day, attaining maximum values when irradiance incident on the sediment surface is higher. (2) This variation may be enhanced by migration of the microalgae, as vertical profiles of biomass with a subsurface maximum may form under high irradiances. (3) As $\Delta F / F_{\mathrm{m},{ }^{\prime} \mathrm{d}}$ increases with light attenuation within the sediment, the overestimation of $\Delta F / F_{\mathrm{m}}{ }^{\prime}$ can be expected to increase towards the end of the low tide period, following sediment desiccation and increasing particle compaction (Brotas et al. 2003). All these factors are likely to confound the characterization of the true variability of effective PSII quantum yield in the microalgal population (Kromkamp et al. 1998, Brotas et al. 2003, Serôdio 2003).

\section{Model assumptions and experimental evidence}

One assumption behind the numerical simulations used in this study is to consider that the $F_{\mathrm{s}}$ and $F_{\mathrm{m}}{ }^{\prime}$ vs $E$ curves are constant over depth, i.e. that the microalgae have the same photophysiological characteristics regarding fluorescence emission at all depths. Under natural conditions this may not be true, as the physical and chemical gradients near the sediment surface, and its interaction with diverse physiological and migratory responses, may affect the patterns of fluorescence 


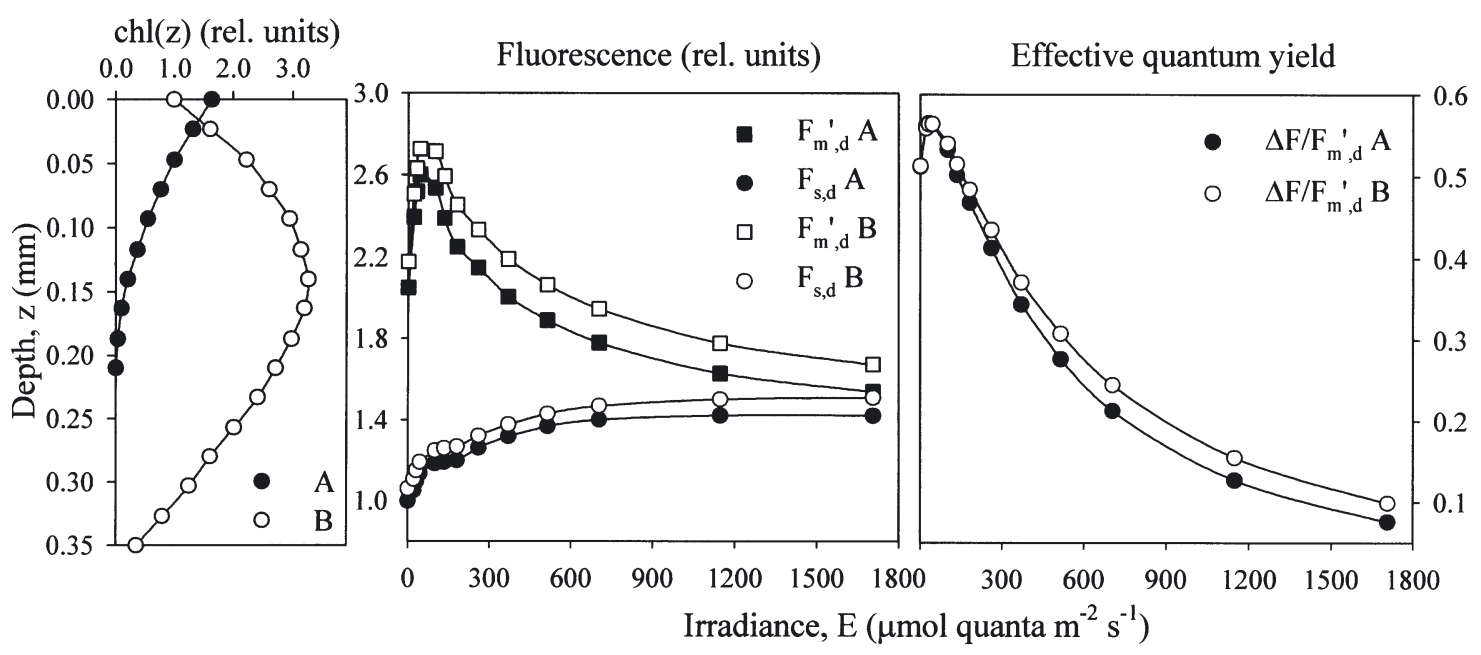

Fig. 8. Example of how changes in microalgal biomass profile, $\operatorname{chl}(z)$, can cause simultaneous increase in $F_{\mathrm{s}, \mathrm{d}}, F_{\mathrm{m}}{ }^{\prime} \mathrm{d}$ and $\Delta F / F_{\mathrm{m}}{ }^{\prime} \mathrm{d}$ under constant irradiance, without requiring changes in the physiological light response of the microalgae. Profiles A and B adapted from profiles of Fig. 4. Fluorescence levels normalised to $F_{\mathrm{s}}(0)$ or $F_{\mathrm{s}, \mathrm{d}}(0)$

emission differently at different depths. Various factors may affect $\phi F$, so that the $F_{\mathrm{s}}$ and $F_{\mathrm{m}}{ }^{\prime}$ vertical profiles will diverge from predictions based on light curves and optical considerations alone: (1) $\phi F$ may increase or decrease due to light-induced vertical migration and replacement of the cells in the upper layers of the sediment. (2) $\phi F$ may be affected by depth-dependent physiological processes associated to non-photochemical quenching, and these may compete with photochemistry for absorbed light energy, leading to a decrease in $\phi F$ under saturating light levels (Schreiber et al. 1986, Kolber \& Falkowski 1993, Müller et al. 2001); these include processes related to energy dissipation in the xanthophyll cycle (energy-dependent quenching, $q_{\mathrm{E}}$ ), and regulated changes in the relative absorption cross section of PSII and PSI and consequent distribution of excitation energy between the 2 photosystems (state I - state II transitions, $q_{\mathrm{T}}$ ). While $q_{\mathrm{E}}$ is the dominant and most rapid of these processes in algae, both processes may lead to similar effects within the time scales of the construction of light curves (Kolber \& Falkowski 1993, Müller et al. 2001). Although expected to take place primarily in the cells near the surface, $q_{\mathrm{E}}$ and $q_{\mathrm{T}}$ may lead to the decrease of the light-saturated part of the $E T R_{\mathrm{d}}$ vs $E$ curve $\left(E T R_{\mathrm{m}, \mathrm{d}}\right)$ below the levels expected from the results of depthintegration alone, in which case the predicted effects on $E T R_{\mathrm{m}}$ and $E_{\mathrm{k}}$ will be overestimated. However, it is also likely that the effects of $q_{\mathrm{E}}$ and $q_{\mathrm{T}}$ in reducing the biases resulting from the use of depth-integrated measurements may be counterbalanced by the downward migration of microalgae responding to excessive irradiance. A third type of non-photochemical quenching related to photoinhibition $\left(q_{\mathrm{I}}\right)$ could, in principle, also affect (decrease) the light-saturated part of fluorescence light curves derived from depth-integrated measurements. However, effects resulting from this type of process can be expected only in light curves based on prolonged light exposure periods and of microphytobenthos communities largely composed by non-motile microalgae.

Another major assumption concerns the optical properties of the sediment, by considering an exponential attenuation of light independently of the microalgal vertical profiles, and by not taking into account light backscattering near the surface (Kühl \& Jørgensen 1994, Decho et al. 2003). However, in spite of these simplifications, experimental evidence supports the main conclusions derived from the numerical simulations, validating the assumptions on which they were based. These effects are also suggested by published data, despite the diversity of sample species composition, experimental conditions, and study site characteristics. Although these results could be due to differences between benthic and planktonic diatoms regarding $E T R_{\mathrm{m}}$, as most data on cultures were obtained with $P$. tricornutum, the overall differences found between suspensions and sediments are unlikely to derive from physiological causes alone, especially considering that cultures are usually grown under optimal conditions. The results of Perkins et al. (2002) also show an increase in the difference between $\Delta F / F_{\mathrm{m}}{ }^{\prime}$, and $\Delta F / F_{\mathrm{m}}{ }^{\prime}$ measured on individual diatoms with irradiance and with fluorescence reabsorption.

The effects described are also expected to occur in other photosynthetic organisms or communities where substantial light attenuation within the sample takes 


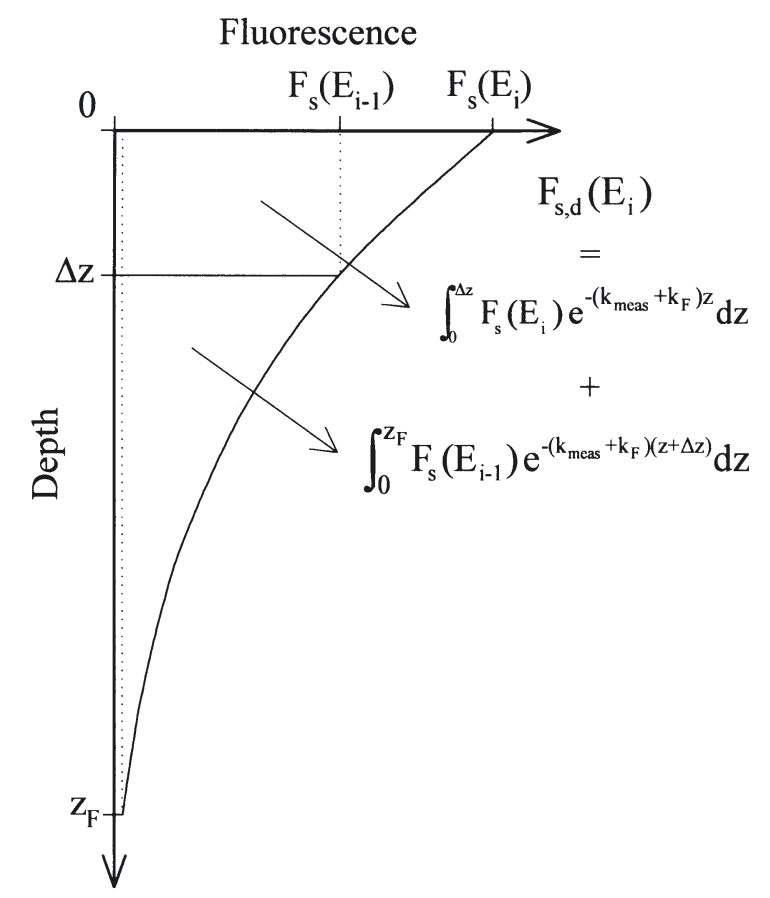

Fig. 9. Illustration of the terms in Eq. (7), regarding the formulation of the set of recursive equations (Eqs. $10 \& 11$ ) to deconvolute fluorescence light curves computed from depthintegrated parameters, and to estimate physiological light response of fluorescence

place, such as leaves of higher plants, macroalgae thalli, lichens, or coral tissues. In either of these cases they are expected to be as complex as in the case of microphytobenthos, because (1) light attenuation within the sample is in many cases only partial (macroalgae thalli, thin plant leaves that exhibit some transparency), and (2) the spatial distribution of lightabsorbing pigments within the sample is invariable over time, causing the relationship between physiological and depth-integrated fluorescence values to remain constant.

\section{Deconvolution of $\Delta F / F_{\mathrm{m}, \mathrm{d}}$, vs $E$ curves}

The characterization of the true physiological light response of benthic microalgae in intact sediment samples requires the elimination of the biases introduced by the use of depth-integrated fluorescence parameters. This can be accomplished through the deconvolution of $\Delta F / F_{\mathrm{m}}$, d vs $E$ curves into depth-independent $\Delta F / F_{\mathrm{m}}{ }^{\prime}$ vs $E$ curves, by means of a recursive equation based on the following rationale: for a given light level $E_{\mathrm{i}}$, the physiological fluorescence level $F_{\mathrm{s}}\left(E_{\mathrm{i}}\right)$ can be related to the depth-integrated levels measured under 2 close light levels $E_{\mathrm{i}}$ and $E_{\mathrm{i}-1}$ by (Fig. 9):

$$
\begin{aligned}
F_{\mathrm{s}, \mathrm{d}}\left(E_{\mathrm{i}}\right) & =\int_{0}^{\Delta z} F_{\mathrm{s}}\left(E_{\mathrm{i}}\right) \mathrm{e}^{-\left(k_{\text {meas }}+k_{\mathrm{F}}\right) z} \mathrm{~d} z \\
& +\int_{0}^{z_{\mathrm{F}}} F_{\mathrm{s}}\left(E_{\mathrm{i}-1}\right) \mathrm{e}^{-\left(k_{\text {meas }}+k_{\mathrm{F}}\right)(z+\Delta z)} \mathrm{d} z
\end{aligned}
$$

(the terms $E_{\text {meas, }} a_{\text {meas }} \phi F_{\mathrm{s}}$ and $G$ of Eq. (2) are not essential for this deduction and have been omitted for simplicity), where $\Delta z$ is the depth interval, so that $E_{\mathrm{i}-1}=E_{\mathrm{i}} e^{-k \mathrm{p} \Delta z}$. Eq. (7) can then be written as:

$$
\begin{aligned}
& F_{\mathrm{s}, \mathrm{d}}\left(E_{\mathrm{i}}\right)= F_{\mathrm{S}}\left(E_{\mathrm{i}}\right)\left(k_{\text {meas }}+k_{\mathrm{F}}\right)^{-1}\left[1-\left(\frac{E_{\mathrm{i}-1}}{E_{1}}\right)^{\frac{k_{\text {meas }}+k_{\mathrm{F}}}{k_{\mathrm{P}}}}\right] \\
&+\left(\frac{E_{\mathrm{i}-1}}{E_{1}}\right)^{\frac{k_{\text {meas }}+k_{\mathrm{F}}}{k_{\mathrm{P}}}} \int_{0}^{z_{\mathrm{F}}} F_{\mathrm{S}}\left(E_{\mathrm{i}-1}\right) \mathrm{e}^{-\left(k_{\text {meas }}+k_{\mathrm{F}}\right) z} \mathrm{~d} z \\
& F_{\mathrm{s}}\left(E_{\mathrm{i}}\right)=\left(k_{\text {meas }}+k_{\mathrm{F}}\right)\left[1-\left(\frac{E_{\mathrm{i}-1}}{E_{\mathrm{i}}}\right)^{\frac{k_{\text {meas }}+k_{\mathrm{F}}}{k_{\mathrm{P}}}}\right]^{-1} \\
& {\left[F_{\mathrm{s}, \mathrm{d}}\left(E_{\mathrm{i}}\right)-F_{\mathrm{s}, \mathrm{d}}\left(E_{\mathrm{i}-1}\right)\left(\frac{E_{\mathrm{i}-1}}{E_{\mathrm{i}}}\right)^{\frac{k_{\text {meas }}+k_{\mathrm{F}}}{k_{\mathrm{P}}}}\right] }
\end{aligned}
$$

As the rationale for $F_{\mathrm{m}}{ }^{\prime}$ is identical, $\Delta F / F_{\mathrm{m}}{ }^{\prime}$ vs $E$ curves can be estimated by applying recursively the following simplified equations to depth-integrated $F_{\mathrm{s}, \mathrm{d}}$ and $F_{\mathrm{m}, \mathrm{d}}$ vs $E$ curves:

$$
\begin{gathered}
\hat{F}_{\mathrm{s}}\left(E_{\mathrm{i}}\right)=F_{\mathrm{s}, \mathrm{d}}\left(E_{\mathrm{i}}\right)-F_{\mathrm{s}, \mathrm{d}}\left(E_{\mathrm{i}-1}\right)\left(\frac{E_{\mathrm{i}-1}}{E_{\mathrm{i}}}\right)^{\frac{k_{\text {meas }}+k_{\mathrm{F}}}{k_{\mathrm{P}}}} \\
\hat{F}_{m}^{\prime}\left(E_{i}\right)=F_{\mathrm{m},{ }^{\prime} \mathrm{d}}\left(E_{\mathrm{i}}\right)-F_{\mathrm{m},{ }^{\prime} \mathrm{d}}\left(E_{\mathrm{i}-1}\right)\left(\frac{E_{\mathrm{i}-1}}{E_{\mathrm{i}}}\right)^{\frac{k_{\text {meas }}+k_{\mathrm{F}}}{k_{\mathrm{P}}}}
\end{gathered}
$$

The success of this method depends on the verification of the assumptions on which it is based, namely a vertically homogeneous photic zone ( $\left.a_{\text {meas }} \phi F\right)$, required for an exponential attenuation of measuring and ambient light, and of fluorescence. The accuracy of the estimates will increase with the proximity between light levels $E_{\mathrm{i}}$ and $E_{\mathrm{i}-1}$ and the decrease of $\Delta z$, which can be achieved by applying Eqs. (10) \& (11) to series of $F_{\mathrm{s}, \mathrm{d}}\left(E_{\mathrm{i}}\right)$ and $F_{\mathrm{m},{ }_{\mathrm{d}}}\left(E_{\mathrm{i}}\right)$ values obtained through interpolation between measured values (typically 7 to $11 E$ levels). Numerical simulations show that interpolation with $\left(E_{\mathrm{i}}-E_{\mathrm{i}-1}\right)=5$ is sufficient to reduce the error in the estimation of $\Delta F / F_{\mathrm{m}, \mathrm{d}}{ }^{\prime}$ to a minimum. The efficiency of this approach was tested by comparing ETR vs $E$ curves with deconvoluted curves estimated by applying Eqs. (10) \& (11) to $E T R_{\mathrm{d}}$ vs E curves, considering the different biomass profiles used above. In the case of the homogenous photic zone, the agreement between original and deconvoluted curves was virtually complete (Fig. 10A). The largest differences were obtained for Profile C1, particularly in the lightsaturated part of the curve, with $E T R_{\mathrm{m}}$ being overestimated by $11.2 \%$ (Fig. 10B). In the case of Profile C2, which represents the most common type of vertical 


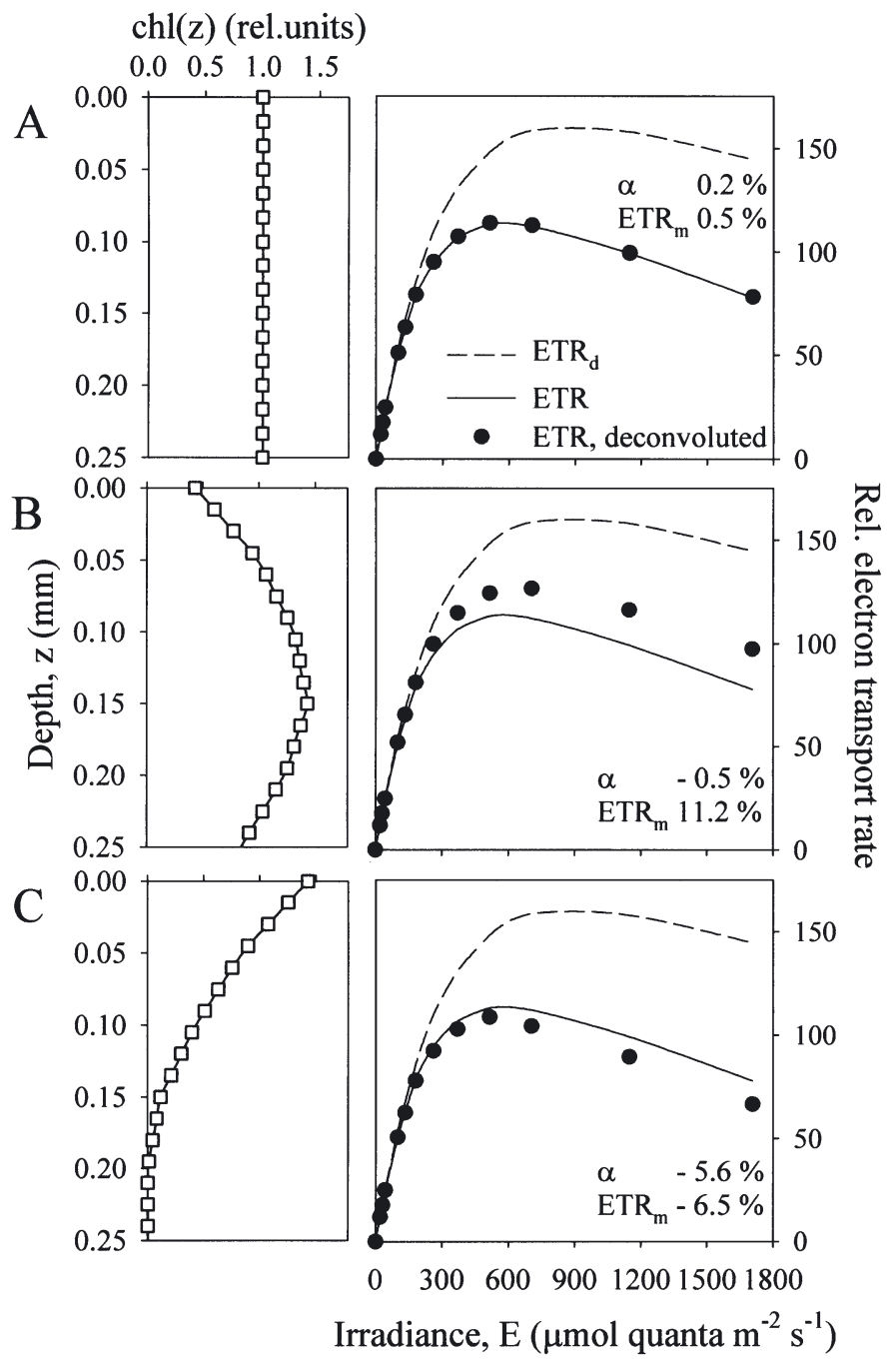

Fig. 10. Deconvolution of $E T R_{\mathrm{d}}$ vs $E$ curves. Effects of microalgal biomass profile, $\operatorname{chl}(z)$, on the efficiency of Eqs. (10) \& (11) to estimate the physiological fluorescence light curves. Profiles of panels A, B and C correspond to Profiles C0, C1 and $\mathrm{C} 2$ in Fig. 4 and Table 2. Numbers represent the difference $(\%)$ between original and deconvoluted light curve parameters $\alpha$ and ETR

profile during day-time low tide (de Brouwer \& Stal 2001, Kelly et al. 2001, Serôdio et al. 2001), ETR $\mathrm{m}$ is underestimated by $6.5 \%$ (Fig. 10C). These values can nevertheless be considered satisfactory since they correspond to a substantial reduction of the error: $-80.2 \%$ (Profile C1) and $-82.8 \%$ (Profile C2).

Acknowledgements. I thank U. Schreiber and R. Gademann for the effort put into the development and testing of the fluorescence emitter-detector unit (WATER-EDF-Universal) used in this work. I also thank A. Calado and A. Tim-Tim for kindly providing unialgal cultures of C. closterium, and S. Cruz, S. Vieira and F. Barroso for help in field and laboratory work.
This work was supported by project PDCTM/MAR/15318/99, funded by Fundação para a Ciência e a Tecnologia. I also thank 2 anonymous reviewers for critical comments on the manuscript.

\section{LITERATURE CITED}

Baillie P (1987) Diatom size distribution and community stratification in estuarine intertidal sediments. Estuar Coast Shelf Sci 25:193-209

Barranguet C, Kromkamp J (2000) Estimating primary production rates from photosynthetic electron transport in estuarine microphytobenthos. Mar Ecol Prog Ser 204: $39-52$

Brotas V, Risgaard-Petersen N, Ottossen L, Serôdio J, Ribeiro L, Dalsgaard T (2003) In situ measurements of photosynthetic activity and respiration of intertidal benthic microalgal communities undergoing vertical migration. Ophelia 57:13-26

Colijn F (1982) Light absorption in the waters of the EmsDollard estuary and its consequences for the growth of phytoplankton and microphytobenthos. Neth J Sea Res 15:196-216

de Brouwer JFC, Stal LJ (2001) Short-term dynamics in microphytobenthos distribution and associated extracellular carbohydrates in surface sediments of an intertidal mudflat. Mar Ecol Prog Ser 218:33-44

Decho AW, Kawaguchi T, Allison M, Louchard E, Reid R (2003) Sediment properties influencing upwelling spectral reflectance signatures: the biofilm gel effect. Limnol Oceanogr 48:431-443

Defew EC, Paterson DM, Hagerthey SE (2002). The use of natural microphytobenthic assemblages as laboratory model systems. Mar Ecol Prog Ser 237:15-25

Falkowski PG, Wyman K, Ley AC, Mauzerall DC (1986) Relationship of steady-state photosynthesis to fluorescence in eucaryotic microalgae. Biochim Biophys Acta 849: 183-192

Flameling IA, Kromkamp J (1998) Light dependence of quantum yield for PSII charge separation and oxygen evolution in eucaryotic algae. Limnol Oceanogr 43:284-297

Geel C, Versluis W, Snel JFH (1997) Estimation of oxygen evolution by marine phytoplankton from measurements of efficiency of photosystem II electron flow. Photosynth Res 51:61-70

Genty B, Briantais JM, Baker NR (1989) The relationship between the quantum yield of photosynthetic electron transport and quenching of chlorophyll fluorescence. Biochim Biophys Acta 990:87-92

Gorbunov MY, Kolber ZS, Lesser MP, Falkowski PG (2001) Photosynthesis and photoprotection in symbiotic corals. Limnol Oceanogr 46:75-85

Gower JFR, Borstad GA (1990) Mapping of phytoplankton by solar-stimulated fluorescence using an imaging spectrometer. Int J Remote Sens 11:313-320

Guillard RRL, Ryther JH (1962) Studies of marine phytoplanktonic diatoms. I. Cyclotella nana Hustedt and Detonula confervaceae (Cleve) Gran. Can J Microbiol 8:229-239

Hartig P, Wolfstein K, Lippemeier S, Colijn F (1998) Photosynthetic activity of natural microphytobenthos populations measured by fluorescence (PAM) and ${ }^{14} \mathrm{C}$-tracer methods: a comparison. Mar Ecol Prog Ser 166:53-62

Henley WJ, Levasseur G, Franklin LA, Osmond CB, Ramus J (1991) Photoacclimation and photoinhibition in Ulva rotundata as influenced by nitrogen availability. Planta 184:235-243 
Ivorra N, Bremer S, Guasch H, Kraak MHS, Admiraal W (2000) Differences in the sensitivity of benthic microalgae to $\mathrm{Zn}$ and $\mathrm{Cd}$ regarding biofilm development and exposure history. Environ Toxicol Chem 19:1332-1339

Jensen M, Feige GB (1991) Quantum efficiency and chlorophyll fluorescence in the lichens Hypogymnia psysodes and Parmelia sulcata. Symbiosis 11:179-191

Kelly JA, Honeywill C, Paterson DM (2001) Microscale analysis of chlorophyll-a in cohesive, intertidal sediments: the implications of microphytobenthos distribution. J Mar Biol Assoc UK 81:151-162

Kolber Z, Falkowski PG (1993) Use of active fluorescence to estimate phytoplankton photosynthesis in situ. Limnol Oceanogr 38:1646-1665

Kromkamp JC, Forster R (2003) The use of variable fluorescence measurements in aquatic ecosystems: differences between multiple and single turnover measuring protocols and suggested terminology. Eur J Phycol 38:103-112

Kromkamp J, Barranguet C, Peene J (1998) Determination of microphytobenthos PSII quantum efficiency and photosynthetic activity by means of variable chlorophyll fluorescence. Mar Ecol Prog Ser 162:45-55

Kühl M, Jørgensen BB (1994) The light field of microbenthic communities: radiance distribution and microscale optics of sandy coastal sediments. Limnol Oceanogr 39: 1368-1398

Kühl M, Glud RN, Borum J, Roberts R, Rysgaard S (2001) Photosynthetic performance of surface-associated algae below sea ice as measured with a pulse-amplitude-modulated (PAM) fluorometer and $\mathrm{O}_{2}$ microsensors. Mar Ecol Prog Ser 223:1-14

Mauzerall D (1972) Light-induced fluorescence changes in Chlorella, and the primary photoreactions for the production of oxygen. Proc Nat Acad Sci USA 69:1358-1362

Müller P, Li XP, Niyogi KK (2001) Non-photochemical quenching. A response to excess light energy. Plant Physiol 125:1558-1566

Neville RA, Gower JFR (1977) Passive remote sensing of phytoplankton via chlorophyll a fluorescence. J Geophys Res 82:3487-3493

Oxborough K, Hanlon ARM, Underwood GJC, Baker NR (2000) In vivo estimation of the photosystem II photochemical efficiency of individual microphytobenthic cells using high-resolution imaging of chlorophyll a fluorescence. Limnol Oceanogr 45:1420-1425

Editorial responsibility: John Dolan, Villefranche-sur-Mer, France
Perkins RG, Underwood GJC, Brotas V, Snow GC, Jesus B, Ribeiro L (2001) Responses of microphytobenthos to light: primary production and carbohydrate allocation over an emersion period. Mar Ecol Prog Ser 223:101-112

Perkins RG, Oxborough K, Hanlon ARM, Underwood GJC, Baker NR (2002) Can fluorescence be used to estimate the rate of photosynthetic electron transport within microphytobenthic biofilms? Mar Ecol Prog Ser 228:47-56

Platt T, Gallegos CL, Harrison WG (1980) Photoinhibition of photosynthesis in natural assemblages of marine phytoplankton. J Mar Res 38:687-701

Schreiber U, Schliwa U, Bilger W (1986) Continuous recording of photochemical and nonphotochemical chlorophyll fluorescence quenching with a new type of modulation fluorometer. Photosynth Res 10:51-62

Schreiber U, Gademann R, Bird P, Ralph PJ, Larkum AWD, Kühl M (2002) Apparent light requirement for activation of photosynthesis upon rehydration of desiccated beachrock microbial mats. J Phycol 38:125-134

Serôdio J (2003) A chlorophyll fluorescence index to estimate short-term rates of photosynthesis by intertidal microphytobenthos. J Phycol 39:33-46

Serôdio J, Marques da Silva J, Catarino F (1997) Nondestructive tracing of migratory rhythms of intertidal microalgae using in vivo chlorophyll a fluorescence. J Phycol 33: $542-553$

Serôdio J, Marques da Silva J, Catarino F (2001) Use of in vivo chlorophyll a fluorescence to quantify short-term variations in the productive biomass of intertidal microphytobenthos. Mar Ecol Prog Ser 218:45-61

Underwood GJC (2002) Adaptations of tropical marine microphytobenthic assemblages along a gradient of light and nutrient availability in Suva Lagoon, Fiji. Eur J Phycol 37: 449-462

Underwood GJC, Nilson C, Sundbäck K, Wulff A (1999) Short-term effects of UVB radiation on chlorophyll fluorescence, biomass, pigments, and carbohydrate fractions in a benthic diatom mat. J Phycol 35:656-666

Warner ME, Fitt WK, Schmidt GW (1996) The effects of elevated temperature on the photosynthetic efficiency of zooxanthellae in hospite from four different species of reef coral: a novel approach. Plant Cell Environ 19: 291-299

William RB (1963) Use of netting to collect mobile benthic algae. Limnol Oceanogr 8:360-361

Submitted: February 10, 2004; Accepted: March 14, 2004 Proofs received from author(s): June 23, 2004 